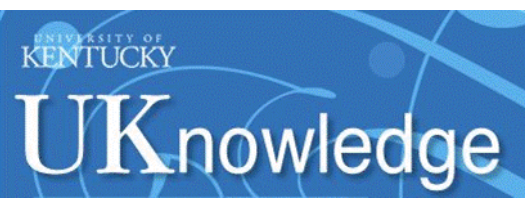

University of Kentucky

UKnowledge

6-1-2009

\title{
Bridging the Gaps: Biomedicine, Complementary and Alternative Medicine in a Holistic Approach
}

Hatim A. Omar

University of Kentucky, hatim.omar@uky.edu

Joav Merrick

University of Kentucky

Follow this and additional works at: https://uknowledge.uky.edu/pediatrics_facpub

Part of the Alternative and Complementary Medicine Commons, Community Health and Preventive Medicine Commons, and the Health Services Administration Commons

Right click to open a feedback form in a new tab to let us know how this document benefits you.

\section{Repository Citation}

Omar, Hatim A. and Merrick, Joav, "Bridging the Gaps: Biomedicine, Complementary and Alternative Medicine in a Holistic Approach" (2009). Pediatrics Faculty Publications. 252.

https://uknowledge.uky.edu/pediatrics_facpub/252

This Article is brought to you for free and open access by the Pediatrics at UKnowledge. It has been accepted for inclusion in Pediatrics Faculty Publications by an authorized administrator of UKnowledge. For more information, please contact UKnowledge@lsv.uky.edu. 


\section{Bridging the Gaps: Biomedicine, Complementary and Alternative Medicine in a Holistic Approach}

\section{Digital Object Identifier (DOI)}

https://doi.org/10.1515/IJDHD.2009.8.2.81

Notes/Citation Information

Published in International Journal on Disability and Human Development, v. 8, issue 2, p. 81-106.

(C) Freund Publishing House Limited

The copyright holders have granted the permission for posting the article here. 


\title{
Bridging the gaps: Biomedicine, complementary and alternative medicine in a holistic approach
}

\author{
Hatim A Omar, MD, FAAP' and Joav Merrick, MD, MMedSci, DMSc ${ }^{1,2,3}$ \\ 'Adolescent Medicine and Young Parent Programs, J422 Kentucky Clinic, Dept. of Pediatrics, Kentucky Children's Hospital, \\ University of Kentucky College of Medicine, Lexington, Kentucky, USA; ${ }^{2}$ National Institute of Child Health and Human \\ Development, ${ }^{3}$ Office of the Medical Director, Division for Mental Retardation, Ministry of Social Affairs, Jerusalem, Israel
}

\begin{abstract}
The $4^{\text {th }}$ international conference on holistic health and medicine was held during September 24-26, 2008 in Lexington, Kentucky in the United States of America. This conference brought many participants from 23 countries, both mainstream health care providers as well as holistic health practitioners to address the latest in knowledge and research, and in turn to find ways to collaborate and work together to provide the best possible care for their patients and clients. These conferences are held to build bridges between the various fractions of medicine and health care providers. The scientific program included plenary sessions, keynotes, workshops and research presentations, which were all peer-reviewed by an international scientific committee. Below we will present the abstracts from the conference.
\end{abstract}

Keywords: Integrative medicine, complementary and alternative medicine, holistic health, human development

Correspondence: Professor Hatim A Omar, MD, FAAP, Director of Adolescent Medicine and Young Parent programs, J422 Kentucky Clinic, Dept. of Pediatrics, Kentucky Children's Hospital, University of Kentucky College of Medicine, Lexington, KY 40536 USA. Tel: 859-323-6426 ext. 311; Fax. 859-257-7706; E-mail: haomar2@uky.edu

Submitted: December 15, 2008. Revised: December 29, 2008. Accepted: January 02, 2009.

\section{INTRODUCTION}

The $4^{\text {th }}$ international conference on holistic health and medicinr. was held during September 24-26, 2008 in Lexington, Kentucky in the USA of America. This conference brought many participants from 23 countries, both mainstream health care providers and holistic health practitioners, to address the latest in knowledge and research and in turn, to find ways to collaborate and work together to provide the best possible care for their patients and clients. These conferences are held to build bridges between the various fractions of medicine and health care providers. The scientific program included plenary sessions, keynotes, workshops and research presentations, all of which were peer-reviewed by an international scientific committee. Below we present the abstracts from the conference.

\section{ABSTRACTS FROM THE CONFERENCE Patterns of complementary and alternative medicine use in an urban population \\ Zahra Yekta, MD, Ahmad Zamani, MD, Morteza Mehdizade, MD and Ziba Farajzadegan, MD \\ Dept. of Community Medicine, Faculty of Medicine, Urmia University of Medical Sciences, Iran and Dept.}

of Community Medicine, Faculty of Medicine, Isfahan University of Medical Sciences, Iran. E-mail: yekta42@ yahoo.com

Background: To determine the prevalence and patterns of Complementary and Alternative Medicine (CAM) use in urban population in Isfahan. Methods: In a crosssectional study through two-stage sampling methods, 870 individuals were selected from Isfahan Province, center of Iran. We selected 20 clusters randomly and chose one household from each cluster by chance then 24 households were included consequently. Subsequently a resident of each household aged 18 years or older was selected randomly. We assessed the rate of use, types of alternative medicine, and conditional disease during recent two years. Results: The overall use of at least one method of complementary and alternative medicine was $62.5 \%$. The most common problems were as follows: digestive problem, obesity and hyperlipidemia, as well as anxiety and depression. Herbal medicine and bless therapy were the most common methods that people chose. Conclusions: Regarding to high prevalence of complementary and alternative medicine use, more attention to complementary and alternative medicine is mandate for physicians and health system managers. 
Health authorities' supervision and training of traditional practitioner is important not only for its economic impact and postponement of seeking treatment, but also for its untoward side-effects either alone or in combination with orthodox medicines.

\section{Future of integrative medicine}

Kathi Kemper, MD, MPH

Caryl J Guth Chair for Holistic and Integrative Medicine, Dept. of Pediatrics, Brenner Children's Hospital, Wake Forest University School of Medicine, Winston-Salem, NC 27157 USA.E-mail: kkemper@wfubmc.edu

Over the past 15 years, there has been enormous activity and growth in the field of complementary, holistic and integrative medicine. At the same time, the world has become "flatter" in terms of a more level playing field with access to information and collaboration via the Internet, cell phones and other technologies. As public interest in natural therapies has grown, barriers to implementation of true integrative care within conventional paradigms have surfaced. Given the variety of stakeholders and geographic variations in values, payment and resources, an organizing vision is necessary for successful collaboration in creating the future. This presentation will review recent trends, underlying values, resources, barriers, and key stakeholders in the process of creating the future of integrative medicine. We will suggest core constituents of successful strategies to create a shared vision of the future of integrative medicine in terms of research, education and clinical care.

\section{Youth health promotion}

Kamilla Bargiel-Matusiewicz, MA, PdD and Agnieszka Wilczyńska-Kwiatek, MA, PdD

Dept. of Psychology, Medical University of Silesia, 12 Medyków Str, 40-752 Katowice (E-mail: kmatusiewicz@) op.pl) and the Institute of Social and Environmental Psychology, Dept. of Psychology and Pedagogics, University of Silesia, 53 Grażynskiego Str, Katowice 40086, Poland (E-mail: awkwiatek@op.pl)

The worsening life conditions of many families in Poland make it difficult for the children and the youth to undergo proper psychosocial development and to gain education. A poor and often disfunctional family is not able to satisfy the basic needs of the child or give support in difficult and decisive moments of development. Alcohol and drug addiction or any other addiction to psychoactive substances constitutes one of the most serious social problems in Poland. We can observe growing consumption of psychoactive substances among children and youth. Prevention is often limited to giving information on what a person must not do and it does not include suggestions connected with constructive ways of coping with problems or of getting satisfaction. The second important problem is connected with disturbances of nutrition. Over half of girls and women see themselves as obese. It is connected with the ideal of slimness, predominating in our culture. The consequences of this growing cult of slimness involve more and more frequent disturbances of nutrition. The problems being the basis for obesity, anorexia and bulimia cannot be reduced merely to nutrition, weight and body size issues. These are indissolubly connected with low self esteem, difficulties in defining one's identity as well as with a lack of satisfactory interpersonal relations. The presented project is prepared for the young people who due to inconvenient social environment conditions are subject to the risk of addiction or disturbances of nutrition. The project contributes to improvement of self-esteem and strengthening of pro-health attitude. The girls and boys taking part in the health prevention classes are becoming more and more conscious of their strong sides. They also begin to pay more attention to health aspects of their existence. This factor is becoming significant in the choice and decision making process. Such an attitude prevents from yielding to trends and fashions that could involve elements adversely affecting health.

Holistic health applications through telehealth for persons with developmental disabilities

Thomas W Miller, PhD, ABPP, Bruce Elliott, PT, Kathy Long, PA-C, Cheryl Mazenac, COTA/L and Michelle Moder, RD

Dept. of Health Promotion, School of Allied Health Science, University of Connecticut, Storrs, CT 062692101,USA.E-mail: tom.miller@uconn.edu

Access to holistic healthcare is examined is the use of telehealth technology in home health care for persons with developmental disabilities. Offered are multidisciplinary contributions to health care services involving physician, nurse and physician assistant health care, therapies including medical, physical therapy, nursing, occupational therapy, speech language pathology and the contributions of dietician and psychologist to the health care needs of persons with developmental disabilities. A telehealth model is offered, as are shifts in health care using telehealth technology in home health care. 
Body reshaping and adult human metamorphosis Søren Ventegodt, MD, MMedSci, EU-MSc and Joav Merrick, MD, MMedSci, DMSci

Quality-of-Life Research Center, Nordic School of Holistic Medicine \& Research Clinic for Holistic Medicine, Copenhagen,Denmark; E-mail: ventegodt@livskvalitet.org; and National Institute of Child Health and Human Development, Jerusalem, Israel; e-mail: jmerrick@internet-zahav.net After holistic existential therapy many patients have noticed a very different experience of their body. They have become more present in it, they have felt better in it, being more accepting, relaxing in the body, and feeling it stronger and more powerful. We know that massage can do this, so that working with deep acceptance of body and sexuality combined with holistic bodywork can do this is not very surprising. What has been a surprise though is the many patients reporting about experience of physical change in their body; often describe that their breast grow, their hips and whole body are reshaped, and often they also tell that they have observed great anatomical changes in their genitals, like a sudden reduction in the size of labia minores, or a broadening of the penis (larger diameter during intercourse). As the bodywork, as often done with the patient undressed, it has sometimes been possible for the therapist to agree in these changes, but as they have been so unexpected we are now only starting to scientifically document the body reshaping. We expect most of the negative experiences of own body to be a product of downgrade metamorphosis, which can be alleviated with upgrade metamorphosis. Now we only need to get the process of metamorphosis under control so well that we can induce it also on cosmetic indication to replace plastic cosmetic surgery, which has so many unwanted side effects. It seems that we actually are able to induce it with the most powerful techniques of holistic existential therapy, if the patient has a strong philosophical interest and if we have a setup where we take care of the patient for some weeks after. The prize of this treatment is believed to be only a fraction of the price of cosmetic surgery, and instead of often-severe negative side effects we expect large positive effects on the patient's QOL, health and ability.

Gender differences in the knowledge and usage of complementary and alternative medicine in undergraduates

Mary Pritchard, PhD, Patt Elison-Bowers, PhD, Phares Book, PsyD and Bobbie Birdsall, PhD

Dept. of Psychology, Boise State University, Boise, Idaho
USA.E-mail: marypritchard@boisestate.edu

The National Institutes of Health has recently opened a center for the study of Complementary and Alternative Medicine (CAM). While NIH has conducted a few random sampling studies, no studies have examined the knowledge and use of CAM in undergraduate students and whether these differ by gender. The present study examined just this. 111 college students $(37$ males, 74 females) at a large, public university in the Pacific Northwest responded to a survey modeled after the one used in the 2004 NCCAM study measuring usage of a variety of CAM techniques, as well as student beliefs and opinions about CAM techniques. A few gender differences emerged. There was a trend for men to rate their health status more positively than women, $\chi^{2}(2)=$ $5.25, \mathrm{p}<.10$. There were a few gender differences in CAM beliefs. For example, women were more likely than men to say that their family members/ relatives/friends used CAM, $\chi^{2}=7.88, p<.05$, that they viewed CAM as credible, $\chi^{2}=5.37, p<.10$, that strong evidence supports the use of CAM, $\chi^{2}=16.84, p<.001$, and that CAM has altered their health beliefs, $\chi^{2}=$ $12.81, \mathrm{p}<.01$. Men were more likely than women to say that conventional medical treatments were more worthwhile than CAM, $\chi^{2}=9.82, p<.01$. Men and women also differed in the types of CAM that they used. For example, women were more likely to use prayer and crystals than were men, whereas men were more likely to use ginseng supplements. Men and women also differed in their usage of various diets, with women using the Zone diet more than men and men using the Atkins and South Beach diets more than women. Finally, women and men differed in their usage of essential oils, with women being more likely to use lavender oil and men more likely to use orange oil.

The genie in your genes

Dawson Church, PhD

PO Box 442, Fulton, CA 95439 USA. E-mail: Dawson @authorspublishing.com

Epigenetic Medicine is a new form of therapy destined to upend many of the certainties of today's medical and psychological practice. Epigenetics shows that genes are activated or deactivated by many factors originating outside the cell and even outside the body. These factors include childhood nurturing, belief, spirituality, prayer, visualization, and the quality of our social network. The most cutting-edge scientific research shows that intention literally affects the conformation of the DNA molecule. Our consciousness is affecting our bodies 
every day. Large-scale scientific studies have shown that success in resolving emotional trauma can lower our chances of getting cancer, heart disease, hypertension, and diabetes. Citing hundreds of scientific studies (Church D. The genie in your genes. Energy Psychology Press, 2007) it is shown how beliefs and emotions can trigger the expression of DNA strands. In this presentation the focus is on a class of genes called Immediate Early Genes or IEGs. These genes turn on within a few seconds of a stimulus. They can be triggered by thoughts or emotions ("I loved that unexpected gift of roses Bill gave me" or "I'm so mad about what Uncle John said at the Christmas party"). Many IEGs are regulatory genes turn on other genes that affect specific aspects of our immune system, such as the production of white blood cells. In this presentation it is shown how we can turn this knowledge to our advantage, engaging powerful epigenetic processes through the quality of our emotions and thoughts, and the nature of our intentions.

The multistream self: Biophysical, mental, social and existential

Vinod D Deshmukh, MD, PhD

Former Associate Professor of Neurology, University of Florida, 3600 Rustic Lane, Jacksonville, Florida 32217, USA.E-mail: vinod38@aol.com

Self is difficult to define because of its multiple, constitutive streams of functional existence. A more comprehensive and expanded definition of self is proposed. The standard bio-psycho-social model of psyche is expanded to biophysical-mental-social and existential self. The total human experience is better understood and explained by adding the existential component. Existential refers to lived human experience, which is firmly rooted in reality. Existential living is the capacity to live fully in the present and respond freely and flexibly to new experience without fear. Four common fears of isolation, insecurity, insignificance, and death can be overcome by developing lifestyle of whole-hearted engagement in the present reality, creative problem-solving, selfactualization and altruism. Such integrative living creates a sense of presence with self-awareness, understanding and existential wellbeing. Wellbeing is defined as a life of happiness, contentment, low distress, and good health with positive outlook. Self is a complex, integrative process of living organisms. Self organizes, coordinates, and integrates energyinformation within and around itself, spontaneously, unconsciously and consciously. Self-process is understood in terms of synergetics, coordination dynamics, and energy-information directed selforganization. It is dynamic, composite, ever-renewing and enduring. It can be convergent or divergent and can function as the source or target of its own behaviormentation. The experience of self is continuously generated by spontaneous activation of neural networks in cerebral neocortex by brainstem-diencephalic arousal system. The multiple constitutive behavioral-mental streams develop concurrently into a unique experience of self, specific for a person at his developmental stage. The chronological neurobehavioral-mental development of self is described in detail from embryonic stage to old age. Self can be behaviorally-mentally oriented and realized in three complimentary modes of being: egocentric, allo-centric, and eco-systemic or existential. The existential mode is both immanent and transcendent and can be self-actualized resulting in a healthy, creative, conflict-frec, and meaningful life.

\section{A study of the impact of Yoga on adolescent girls} Nancy L Bloemer, ThD, RYT, LMT

Registered Yoga Teacher and Massage Therapist, Melbourne, Kentucky, USA. E-mail: nbloemer@fuse.net Adolescents, particularly females, undergo physical and emotional challenges many of which impact their short and long term health. Self care practices such as yoga have been documented as helpful in coping with stressful circumstances; however few studies have addressed specifically their effectiveness in a population of adolescent girls. The purpose of this study was to assess the impact of a weekly yoga based practice of body awareness and intentional relaxation on self rated affect and perceived stress levels in adolescent girls. The intervention group $(n=47)$ participated in six 50 min, yoga based sessions over a seven week period. Dependent variable scores were compared to a control group $(n=40)$ over the same time frame. Both groups completed the Positive and Negative Affect Schedule (PANAS) and the Perceived Stress Scale (PSS) one week prior to and one week after the intervention sessions. The perceived stress scores of the adolescent girls who practiced the yoga based practice decreased significantly over time as compared to the control group. Positive affect scores improved over time in the intervention group but only in those adolescent girls who participated in five or more sessions. Negative affect scores did not change significantly over time in either the control or intervention groups. Discussion of 
possible explanations for the changes observed and implicat:ons for future research will be presented.

\section{Condom use after voluntary counseling and testing among youth in Rwanda \\ Condo Jeanine, MD, MSc ${ }^{1}$, Ntaganira Joseph, MD, MPH', Ntahobakulira Isaac, $\mathrm{MPH}^{\prime}$ and Janet Rice, $\mathrm{PhD}^{2}$ \\ 'School of Public Health, National University of Rwanda, Rwanda; e-mail: jeaninecondo@yahoo.fr; ${ }^{2}$ School of Public Health and Tropical Medicine, Tulane University, USA}

Background: The present study examined rate and predictors of condom use among youth aged 15 to 21 years in the southern region of Rwanda. The study compares youth who received voluntary counseling and testing (VCT) services from the Population Services International (PSI) that provides youth friendly services, as opposed to those who received VCT services from general government health center. Method: Data was collected based on health facility records (PSI and Government health center). A cross sectional study design was performed and a total of 273 youth were selected based on simple random sampling method and interviewed based on a semi structured questionnaire. The survey gathered information on socio demographic characteristics, general knowledge and use of condom among surveyed youth. Results: The results from univariate analysis indicate that a small proportion of youth fiom PSI (16\%) and government (10\%) have knowledge of where to buy a condom and of advantages and disadvantages of using a condom. Only $20 \%$ of youth reported having bought condoms in the last 6 months after undergoing voluntary counseling and testing (VCT) for HIV. This study found that access to reproductive health services is not a constraint: almost all youth (93\% Government health center and $71 \%$ PSI) reported no difficulties of accessing reproductive health services. The multivariate analysis using forward procedure included score from Principal Factor Analysis (PFC) on self esteem, parents' support found that non married youth were 6 times more likely to use condoms then married youth $(P<0.01)$. Analysis also found that male youth, who have two parents as well as a high score on a self confidence scale, were predictors of appropriate condom use. Recommendations: Findings suggest that VCT services should focus more on youth by using concise messages on sexual education that include the availability of contraceptive products. Condom use and related knowledge after up taking VCT services are generally low ( $16 \%$ and $20 \%$ respectively). Building self esteem during individual counseling and education session are recommended for protecting youth from not using condom.

The evolution of holistic foods and risk of cardiovascular disease

Ram B Singh, Fabien DeMeester, Lekh Juneja and F Mustafa

Halberg Hospital and Research Institute, Columbus Paradigm Institite, Bastogne, Belgium, Taiyo Kagaku, Yokkaichi, Japan and Civil Lines, Moradabad, India.

E-mail: icn2005@sancharnet.in oricn2008@mickyonline.com

The history of evolution of human beings indicate that our early diet included natural foods, fruits, vegetables, green vegetables, eggs and honey. Fish and meat were also available to pre-agricultural humans, which shaped modern human genetic nutritional requirement. Cereal grains and vegetable oils that are rich in $\Omega-6$ fatty acids are relatively recent addition to the human diet that represents dramatic departure from those foods to which we are adapted. The role of fatty acids in the prevention and pathogenesis of cardiovascular disease (CVD), type 2 diabetes, and insulin resistance are well known. Excess linoleic acid, trans-fatty acids (TFA), saturated and total fat, as well as refined starches and sugar are proinflammatory. Low dietary monounsaturated fatty acids (MUFA) and n-3 fatty acids and other long chain polyunsaturated fatty acids (LCPUFA) are important in the pathogenesis of metabolic syndrome leading to CVD. Sedentary behavior in conjunction with mental stress and various personality traits can enhance sympathetic activity and increase the secretion of catecholamine, cortisol and serotonin that appear to be underlying mechanisms of obesity and metabolic syndrome. Excess secretion of these neurotransmitters in conjunction of underlying long chain PUFA deficiency, and excess of proinflammatory nutrients, may damage the neurons via proinflammatory cytokines, in the ventromedial hypothalamus and insulin receptors in the brain, especially during fetal life, infancy and childhood, resulting into their dysfunction. As $30 \%-50 \%$ of the fatty acids in the brain are LCPUFA, especially omega-3 fatty acids, which are incorporated in the cell membrane phospholipids, it is possible that their supplementation may be protective. Omega-3 fatty acids are also known to enhance parasympathetic activity and increase the secretion of 
anti-inflammatory cytokines IL-4 and IL-10, as well as acetylcholine in the hippocampus. Possibly a marginal deficiency of LCPUFA, especially n-3 fatty acids, due to poor dietary intake during the critical period of brain growth and development in the fetus and infant, and possibly in the child, in adolescents, and in adults, may enhance oxidative stress and the release of the proinflammatory cytokines tumor necrosis factor-alpha, interleukins 1,2, and 6, and cause neuronal and beta-cell dysfunction. The Indo-Mediterranean diet heart study and the Indian Experiment of Infarct Survival as well as diet and Reinfarction trial and the studies conducted by Renaud from France indicate that treatment with diets rich in MUFA and omega-3 fatty acids are important in the prevention of CVD.

Mindfulness based health care interventions. The basis for truly holistic medicine

Michael de Vibe, MbBCh

Family physician and family therapist, Senior advisor, Nornvegian Knowledge Centre for the Health Services, Oslo, Nonway. E-mail: mdevibe@online.no

Mindfulness is defined as being fully present and paying attention to what is happening now with an open heart and an open mind. It is an ancient discipline to train the human mind. Its fruits are empathy, connectedness and compassion, vital to any health practitioner that has the ambition to treat the whole person and being sensitive to the cultural context that is present. The presentation will focus on the relevance of mindfulness practice for holistic health parishioners and holistic medicine.

\section{Blood lipid composition as a marker for holistic health. The Columbus concept \\ Fabien De Meester, PhD \\ Columbus Paradigm Institute SA, Chaussée de Tervuren 149, 1410 Waterloo, Belgium. E-mail: Fabien.DeMeester @bnlfood.com}

Blood lipid composition does reflect one's health status: (a) circulating serum lipoproteins and their ratio provide information on their atherogenicity to blood vessels and (b) circulating plasma fatty acids give indication on proinflammatory status of blood vessels.; (a) and (b) are phenotype-related and depend on genetic, environmental and developmental factors. As such, they appear as universal markers for holistic health. Blood cholesterol is central to this approach. Its 3D-representation shows how circulating lipoproteins affect blood vessels integrity upon their circulating throughout the body. Of major importance appear the essential dietary nutrients (essential amino acids, fatty acids, antioxidant vitamins and minerals) and the functional component of the regimen (diet, sport, spiritualism, etc). An example is given of an essential dietary nutrient and of a functional component of man's regimen that affect health in a predictive way derived from the $3 \mathrm{D}$ representation of blood cholesterol.

Assessment of the role of forum theatre in HIV/AIDS behavioral change process among secondary school adolescents in Butare province, Rwanda

Paulin Basinga, MD, MSc, Jean de Dieu Bizimana, MSc and Cyprien Munyanshongore, $\mathrm{PhD}$

Tulane University and Dept. of Reproductive Health, Rwanda School of Public Health, National University of Rwanda, Rwanda. E-mail: paulinbasinga@gmail.com Since the beginning of the HIV/AIDS pandemic, subSaharan Africa is one of the regions most severely affected by the infection. In general, theatre is intuitively considered as an efficient sensitization tool that can lead to a sustainable behavior change. Objective: This study evaluates the efficiency of forum theatre in comparison with the classical HIV/AIDS sensitization to impact the knowledge, attitudes and practices of the youth in secondary schools. Methods: This research-action used the "pre- and post-test" assessment method. Two different interventions in two secondary schools in Butare town were compared. During the month of May 2005, three forum theatre interventions were performed for the students of the Butare Official Secondary School (intervention group) and two classical sensitization sessions in the Baptist Lower Seminary (control group). Observation was carried out in the following six months. The final quantitative assess-ment was carried out during the month of November 2005. In total, 11 indicators were selected to serve as a basis for the comparison between the two schools. Results: The homogeneity test showed no statistically significant difference between the two schools. Impact assessment at 6 months could not demonstrate statistically significant differences for behavioral variables due to the short observation period. However, the study showed that the classical education good in improving knowledge and the forum theatre boost more the practices toward adoption of safe sex. Recommendations: Both methods can be used for the sensitization of youth and emphasis of strength of each method in impacting the behavior need to be considered. 
Holistic medicine for beginners. Getting started with a quick course in clinical holistic medicine.

Søren Ventegodt, MD, MMedSci, EU-MSc-CAM (complementary, psychosocial and integrative health sciences)

Quality-of-Life Research Center, Nordic School of Holistic Medicine \& Research Clinic for Holistic Medicine, Copenhagen, Denmark.E-mail: ventegodt@livskvalitet.org

Target group: MDs, RNs, physiotherapists, body workers, and other health practitioner who want to be introduced to holistic medical theory and use simple but efficient tools from the holistic medical toolbox in their own practice. Ambition: After the course, the participants will be able to (1) do holistic therapy to help patients with both physical and mental problems; and (2) document the effect of therapy using a small and easy, validation questionnaire on quality of life and selfassessed physical and mental health (QOLl and QOL5 combined). Background: Clinical holistic medicine seems to be en efficient new combination of well known therapeutic tools that can help one in two patients with physical illness and chronic pain, mental illness, sexual problems, low self-esteem and low quality of life. Most interestingly the tools are so simple that everybody with a "holistic worldview" can learn to use them in a couple of days, providing a new set of safe and efficient therapeutic tools to doctors, nurses, therapists and other health providers.

Dilated cardiomyopathy in children and young adults: What is new?

Galal EN Elkilany, MD, FESC, FISCU Mustafa A ALQbandi, MD, DCH, FAAP, FRCPC, FSCAI and Khaled A Sayed, MSc, MD

Cardiology Dept., Echocardiography Laboratory, Chest Hospital, State of Kuwait, Safat, Kuwait. E-mail: galal_ elkilany@yahoo.com

Dilated cardiomyoathy (DCM) is the most common form of cardiomyopathy and cause of cardiac transplantation in children and young adults. Mortality is still high among such patients population. Yet, mortality, clinical sourse and illustrative echocardiographic data of DCM in children and young adults are not well established. Objectives: To provide a review of detailed description of the incidence, causes, outcomes, related risk factors and new echocardiographic criteria of risk of death from DCM. Conclusion: In children and young adults DCM is a diverse disorder with outcomes that depend largely on cause, age, heart failure status at presentation and echocardiographic parameters of the heart (systolic and diastolic function of left ventricle, shape of the left ventricle, thickness, synchronization of contractility of cardiac segments and valvular function of mitral valve). This presentation will present new findings in the diagnostic area.

Engaging the faith community as partners in health Janice Kuperstein, PT, MSEd, Doctoral Candidate Department of Rehabilitation Sciences, College of Health Sciences, University of Kentucky, Charles T. Wethington Jr. Building, 900 South Limestone St, Lexington, KY USA. E-mail:jkupe0@email.uky.edu

The faith community has historically been a facilitator of health and healing and has more recently recognized its role in health promotion as part of that mission. In the twelfth century, health care was listed first by Maimonides on his list of the ten most important communal services that had to be offered by a city to its residents (Mishneh Torah, Sefer Hamadda IV:23). In more modern times, faith based institutions and health ministries of various kinds have emerged in all major denominations as a way to promote health, and provide access to care. Faith communities are the most significant membership organizations in the USA and in many other nations throughout the world and have many characteristics making them exceptional partners in promoting health of body mind and spirit. Objectives: Identify key advantages of a health-faith partnership; Discuss common types of faith-based interventions for health; Examine outcomes in specific categories of intervention; Identify opportunities for health promotion through faith communities; Identify opportunities for research. Methods: Lecture, discussion, small group work in the form of a workshop.

The role of faith community nurses in assisting older adults with healthcare navigation

Janice Kuperstein, PT, MSEd, Doctoral Candidate Department of Rehabilitation Sciences, College of Health Sciences, University of Kentucky, Charles T. Wethington Jr. Building, 900 South Limestone St, Lexington, KY USA. E-mail:jkupe0@email.uky.edu

Although the United States currently spends approximately $16 \%$ of its GDP on healthcare, more per capita than any other nation, US citizens do not enjoy health outcomes commensurate with this investment. Failures to coordinate care, especially during transitions among healthcare settings, and missed opportunities to involve chronically ill adults in decision-making have been identified. Especially for individuals with multiple chronic conditions, achieving an acceptable quality of life 
depends upon the coordination of multiple dimensions of care on biomedical, psychosocial, and spiritual levels. Despite this need, the current healthcare system consists primarily of silos for delivery of care. and many patients, often those least capable of system navigation, are left moving among multiple providers and settings. Because most chronic conditions require ongoing self-management, lack of coordinated communication results in inadequate care, poor follow-through, and negative health outcomes. The role of spirituality in health and wellbeing is largely overlooked in healthcare practice, despite robust literature acknowledging its importance. Faith communities are an important potential source to stem the current navigational crisis, in particular through the expanding practice of faith community nursing. Services provided by faith community nurses (FCNs) are provided within the context of spirituality and include education, screening, counseling, and advocating/facilitating. Objectives: Understand the types of services offered by FCNs within congregations in Kentucky; Identify the frequency and type of assistance provided in navigating the healthcare system, including medical and social, throughout the continuum of care; Identify the FCNs knowledge base in identifying risks of functional decline and resources available in both the biomedical and home based systems; Identify the types of screens actually employtd; Understand interventions provided in practice. Methods: Mixed quantitative (survey) and qualitative (semi-structured interviews). Results: After completion the results will be analyzed and presented at the conference.

Beating the odds: A qualitative study of Chinese female university students growing up in economic disadvantaged families

Vera MY Tang, MPhil, BSSc and Daniel TL Shek, BSocSc, PhD, FHKPS, BBS, JP

Social Welfare Practice and Research Centre, Dept. of Social Work, The Chinese University of Hong Kong.

E-mail:mytang@swk.cuhk.edu.hk

By adonting a holistic perspective with ecological emphases, this study attempted to gain an in-depth understanding of how Chinese female university students growing up in economic disadvantaged families develop in holistically across time. Twenty-one semi-structured interviews based on seven Chinese female university students growing up in single-mother families receiving welfare participated in this study. The qualitative findings revealed several themes: (1) the participants believed that the main cause of their families in need of receiving welfare was the low educational attainments of their parents, which corresponded to their beliefs held from childhood to their present lives about having a better future life through obtaining higher education qualification; (2) the qualities of 'good child' emphasis in the Chinese culture helped them to maintain positive attitudes towards the experiences of poverty and demands in the families from childhood to their present lives; (3) they perceived the difficult growth trajectories as the "blessings in disguise"; and (4) five protective factors brought them through the difficult past including (a) hope for a better future, (b) family orientation, (c) their mothers, (d) emotional support from non-relatives and relatives, and (e) positive perspective towards adversity. The present findings suggest that although disadvantaged circumstances in childhood and adolescence could limit one's options and opportunities, adolescents could break the cycle of disadvantage if they could see the positive meaning of those experiences later in adolescence or adulthood. Family life quality is also an important factor influencing the well-being of the participants. A holistic and positive youth development approach is recommended to be adopted when working with single-mother welfare recipients and their children who undergo multiple difficulties.

Subjective Outcome Evaluation Findings Based on the Project P.A.T.H.S.: Profiles and Correlates

Britta M Lee', MDes, BBA, Vera MY Tang' ${ }^{2}$ BSocSc, MPhil, Daniel TL Shek ${ }^{3}$, BSocSc, PhD, FHKPS, BBS, JP

${ }_{1,2}$ Social Welfare Practice and Research Centre, Dept. of Social Work, The Chinese University of Hong Kong Correspondence: Britta M. Lee, MDes, PhD student, Dept. of Social Work, The Chinese University of Hong Kong, Shatin, Hong Kong. Tel: 852-2609-7375. Fax: 852-2603-5018. E-mail: bmlee@sw'k.cuhk.edu.hk. Webpage: http://web.swk.cuhk.edu.hk

The purpose of this paper is to report subjective outcome evaluation findings collected from the Project P.A.T.H.S. (Positive Adolescent Training through Holistic Social Programmes) which is a positive youth development program which attempts to promote holistic adolescent development in Hong Kong. A total of 4,738 students from 24 experimental schools participated in the Tier 1 Program of the project. After the program was completed, the participants completed a self-administered 20 -item Chinese Subjective Outcome Scale (SOS) which assessed the participants' perceptions of the program, instructor(s), effectiveness, degree of sharing with the significant others and global impression. Results showed that the Chinese SOS 
possessed acceptable psychometric properties. The scale was internally consistent and the related dimensions regarding the program, instructor(s), effectiveness, sharing and global impression domains were significantly associated among themselves. The Chinese SOS scores were significantly related to the objective measure of life satisfaction at pretest and posttest as well as the change score, thus providing support for the construct validity of the scale. Regarding the profiles of the responses, roughly $82 \%$ of the respondents regarded the program to be effective and the program promoted self-understanding in the participants. Several psychosocial correlates of subjective outcome evaluation assessed by the SOS, including gender, economic disadvantage, perceived school adjustment and perceived family relationships, were found.

Tier 1 program of the project P.A.T.H.S. in Hong Kong: Evaluation findings based on interim evaluations and students' diaries

Rachel Chui Fun Sun, BSocSc, PhD and Daniel, Tan Lei Shek, BSocSc, PhD, FHKPS, BBS, JP

Social Welfare Practice and Research Centre, Dept. of Social Work, The Chinese University of Hong Kong. Email: cfsun@swk.cuhk.edu.hk

This presentation reports the interim evaluations and evaluations on students' weekly diaries to understand the implementation quality of the Tier 1 Program of the Project P.A.T.H.S. For the interim evaluations, 25 and 100 schools participating in the Secondary 1 Program in the Experimental Implementation Phase (EIP; 2005-06) and Full Implementation Phase (FIP; 2006-07), respectively and 25 schools participating in the Secondary 2 Program in the Experimental Implementation Phase (EIP; 2006-07) were randomly selected to participate in personal and/or telephone interviews regarding the quality of the implementation process of the Tier 1 Program. Results showed that most respondents (program implementers) perceived that the students had positive responses to the program and the program was beneficial to the students. The respondents identified several good aspects in the program although negative comments on the program design and difficulties in the implementation process were also recorded. In the coming conference, additional findings generated from the Secondary 2 Program (FIP; 2007-08) and Secondary 3 Program (EIP; 2007-08) will be presented.

For the evaluations on students' weekly diaries, four schools participating in the Secondary 1 Program (EIP; 2005-06) were randomly selected and their students were invited to write a reflective journal in the form of weekly diary to reveal their perceptions and feelings regarding the Tier 1 Program. Results of the qualitative findings showed that most of the respondents had positive views on the program and the instructors, and stated that they had acquired competencies at societal, familial, interpersonal and personal levels after joining the program. In the coming conference, additional findings generated from the Secondary 1 Program (FIP; 2006-07) and Secondary 2 Program (EIP; 2006-07) will be presented. In sum, the above findings provide additional support for the effectiveness of the Tier 1 Program of the Project P.A.T.H.S. in Hong Kong.

Developing and evaluating a model of suicidal ideation for Hong Kong Chinese adolescents

Rachel, Chui Fun Sun, BSocSc, PhD

Social Welfare Practice and Research Centre, Dept. of Social Work, The Chinese University of Hong Kong. Email: cfsun@swk.cuhk.edu.hk

This presentation reports parts of a doctoral research study. The main study aimed to develop a model of suicidal ideation which included family cohesion, family conflict, teacher support, sense of school belonging, academic pressure, peer support and peer conflict as antecedent predictors; and self-esteem and depression as mediators, by using structural equation modeling. Data was collected from questionnaires completed by 1,358 adolescents. The results showed that only family cohesion, sense of school belonging and peer support made a significant difference for prediction of self-esteem and depression, and that depression was the most significant mediator of suicidal ideation. Peer support and peer conflict were found to act differently as predictors of suicidal ideation between boys and girls, and between younger and older adolescents. A follow-up qualitative study was carried out that aimed to collect empirical information to supplement the quantitative findings and to explore the support mechanism of family, school, and peer systems for maintaining adolescent psychological health. It involved interviews with fifteen adolescents with high levels of suicidal ideation. The findings revealed that adolescents with severe suicidal ideation not only had to encounter several stressors, such as parent-child conflict, classmate victimization and rejection, but also perceived themselves as having low support from their family, school and peers, which contributed to feelings of worthlessness, helplessness, depression, and subsequent suicidal thoughts. This study pointed to an 
intimate interpersonal relationship in family, school and peers was the key to unlocking these support systems. Both quantitative and qualitative findings highlighted the significant contribution of school and peer factors, in addition to that of family and psychological factors, to the prediction of suicidal ideation in a Chinese context. Practical implications on school guidance for enhancing adolescent psychological well-being are considered, and the implications of this research for future studies are also discussed.

Positive youth development programs targeting at students with greater psychosocial needs: Findings based on three subjective outcome evaluation studies Tak Yan Lee', BSocSc, MSW, PhD \& Vera MY Tang', BSocSc, MPhil

'Dept. of Applied Social Studies, City University of Hong Kong; ${ }^{2}$ Social Welfare Practice \& Research Centre, Dept. of Social Work, The Chinese University of Hong Kong. Correspondence: Tak Yan Lee, Dept. of Applied Social Studies, City University of Hong Kong, Kowloon, Hong Kong. Tel: 852-2788-8978. Fax: 852-2788-8960. E-mail: ty.lee@cityu.edu.hk.Webpage: http://wwwv7.cityu.edu.hk sspltr/ty/tycv/

This presentation reports and compares the findings from three conort studies of subjective outcome evaluation on the Project P.A.T.H.S. The Project provides resources for participating schools to design and implement the Tier 2 Program for adolescents with greater psychosocial needs on top of the Tier 1 Program targeting all Secondary 1 to 3 students in the school through three consecutive years. Initial findings supported the effectiveness of the Tier 2 Program (Secondary 1 Curriculum) in the Experimental Implementation Phase (EIP-S1: 2005-06) using subjective outcome measures. This paper will present findings of two further studies on the Tier 2 Program. The first was on Secondary 2 students (EIP-S2: 2006-07) who might have participated in the Tier 2 Program in the previous school jear (EIP-S1: 2005-06). The second was on Secondary 1 students who joined the Tier 2 Program for the first time in the Full Implementation Phase (FIP-S1: 2006-07). After completion of the Tier 2 Program, students responded to the Subjective Outcome Evaluation Form (Form $\mathrm{C}$ ) assessing their views on the program, instructors and perceived effectiveness of the program. Based on the consolidated reports submitted by the agencies to the funding body, the consolidated data will be aggregated to form a "re-constructed" overall profile on the perceptions of the program participants. The types of program will be classified to facilitate comparisons across cohorts. Data are being analyzed. Comparisons of the findings from the three cohort studies will be made. Limitations will be highlighted.

Process evaluation of the Tier 1 Program of the project P.A.T.H.S.: Findings based on three cohort studies Tak Yan Lee, BSocSc, MSW, PhD' and Rachcl, Chui Fun Sun, BSocSc, PhD ${ }^{2}$

'Dept. of Applied Social Studies, City University of Hong Kong; ${ }^{2}$ Social Welfare Practice and Research Centre, Dept. of Social Work, The Chinese University of Hong Kong.E-mail: ty.lee@cityu.edu.hk

While the outcomes of the Tier 1 Program (Secondary 1 and 2 Curricula) of the Project P.A.T.H.S. in both the Experimental Implementation Phase (EIP-S1: 2005-06 and EIP: S2: 2006-07) and the Secondary 1 Curriculum of the Full Implementation Phase (FIP-S1: 2006-07) were confirmed through studies using subjective and objective measures, it is necessary to provide evidence that the outcomes of the Program were contingent on the quality of program implementation. The paper will present findings of three process evaluation studies to demonstrate the coherence between the intended and the delivered program contents. To understand the implementation quality of the Tier 1 Program delivered in two consecutive years (EIP-S1: 2005-06; EIP-S2: 2006-07; and FIP-S1: 2006-07), observers carried out process evaluation in the form of systematic observations of selected curriculum units in randomly selected schools. The results showed that the overall level of program adherence was generally high, ranging from $70 \%$ to $95 \%$ (EIP-S2: 2006-07; average: $83.6 \%$ ), $50 \%$ to $95 \%$ (EIP-S1: 2005-06; average: $84.5 \%$ ), and $45 \%$ to $100 \%$ (FIP-S1: 2006-07; average: $86.3 \%$ ). The respective inter-rater reliability were 0.94 (EIP-S2: 200607), 0.81 (EIP-S1: 2005-06), and 0.88 (FIP-S1: 2006-07). In the 2006-07 studies (EIP-S2 and FIP-S1), high implementation quality of the program in the areas of student interest, student participation and involvement, classroom control, use of interactive delivery method, use of strategies to enhance student motivation, use of positive and supportive feedbacks, instructors' familiarity with the students, degree of achievement of the objectives, time manage-ment, lesson preparation, overall implementation quality, and success of implementation was also found. In the 2005-06 (EIP-S1) study, except for two specific areas, i.e., use of positive and supportive feedbacks as well as time management, all the other areas was rated as positively high. Despite limitations, the findings suggest that the implementation quality of the 
Tier 1 Program both in the Secondary 1 and 2 Curricula of the Experimental Implementation Phase (EIP-S1: 2005-06 and EIP-S2: 2006-07) and the Secondary 1 Curriculum of the Full Implementation Phase (FIP-S1: 2006-07) was high and provide supporting evidence to account for the successful and encouraging outcomes of a major positive youth development program.

Efficacy of a homeopathic association for the prevention of common respiratory infections in highly susceptible children: A randomized controlled trial Giuseppe Rocca' and Maria Colombo ${ }^{2}$

'Direzione Scientifica of Fondazione Ospedale Maggiore Policlinico Mangiagalli e Regina Elena, Milan, Italy and ${ }^{2}$ Pediatrician, Azienda Sanitaria Locale 2, Milan, Italy. E-mail: bepperocca@policlinico.mi.it

The prevention of common respiratory infections is often unsatisfactory and the abuse of antibiotics for this indication is diffuse. We assessed the preventive efficacy of an association of homeopathic medicines in 2-6 years old susceptible children. Children with a history of four respiratory infections in the previous year were randomized to Omeogriphio a homeopathic association of 3 nosodes: Anas barbariae $200 \mathrm{~K}$, Influencinum $9 \mathrm{CH}$, Vinceto:icum $5 \mathrm{CH}$ and 4 classic homeopathic medicines: Aconitum napellus $5 \mathrm{CH}$, Belladonna $5 \mathrm{CH}$, Echinacea 3 $\mathrm{CH}$ and Cuprum $3 \mathrm{CH}$, administered orally once a week for 6 consecutive weeks, starting at the beginning of October, or to the control group and were evaluated on a strict intention to treat basis. Two efficacy end points were analyzed as follows: (i) reduction of antibiotic use, (ii) reduction of the incidence of infections. Prevention reduced the percentage of episodes of infections treated with antibiotics from $60 \%$ to $45 \%(\mathrm{P}=0.02)$ acting selectively in pharyngitis, tonsillitis and bronchitis $(P=0.01)$. It selectively reduced the incidence of otitis $(\mathrm{P}=0.04)$, tonsillitis $(\mathrm{P}=0.03)$ and bronchitis $(\mathrm{P}=0.05)$. Prevention with homeopathic medicines reduces both antibiotic prescriptions and incidence of specific respiratory infections.

Severe acute maternal morbidity. Dilemma of rural women

Rozina Mustafa, MD and Haleema Hashmi, MD

Baqai Medical University, Karach, Pakistan. E-mail: roz_mustafa@yahoo.com

In developing countries like Pakistan, $76 \%$ of the population still resides in rural areas. Rural women have inadequate access to obstetric care options and poor knowledge of obstetric complications. Consequently,
$70 \%$ of deliveries are still conducted by Traditional Birth Attendants resulting in more maternal morbidities and mortalities. Objectives: To determine the incidence of severe acute maternal morbidity (SAMM) and its ratio to maternal mortality and to assess whether SAMM can be used as a surrogate for maternal death enquiries. Study design: Descriptive study from 1st January 2006 till 30th September 2007. Methodology: The study was conducted in the Obstetric Unit of Fatima Hospital, Baqai Medical University. This tertiary care hospital is situated $20 \mathrm{~km}$ far from Karachi city in Gadap area to serve the rural population. Severe acute maternal morbidity (SAMM) case definition was based on validated specific criteria comprising five diagnostic categories: hemorrhage, hypertensive disorders in pregnancy, dystocia, infection, and anemia. Results: There were 1,551 deliveries, 83 cases of severe acute morbidity and 8 maternal deaths during the study period. The incidence of SAMM is $53.5 / 1000$ deliveries. The Maternal death to SAMM ratio is $1: 10$. The most common obstetric diagnoses of SAMM were anemia, ante-partum and postpartum hemorrhage responsible for $22.8 \%, 20.4 \%, 20.4 \%$ respectively. Dystocia and Severe hypertensive disorders in pregnancy accounted for $18 \%$ and $10.8 \%$ of morbidities. Pregnancy related sepsis was responsible for $3.6 \%$. However, the causes of maternal deaths were postpartum hemorrhage and sepsis, respectively responsible for $75 \%$ and $25 \%$. The severe morbidities on arrival were $\mathbf{8 0 . 7 \%}$ and during hospitalization $19.2 \%$. All maternal deaths occurred in patients who arrived with life threatening complications. Organ system dysfunction/failure was diagnosed in $22.8 \%$ of SAMM patients. Conclusion: The information of SAMM is more meaningful in assessing the quality of care of an institution. This study appears feasible \& sustainable and provides valuable information towards improving deficiencies in maternal care. However review of SAMM gives a different disease pattern to that obtained from maternal deaths.

Alcohol and prevention from a holistic perspective Trine Flensborg-Madsen, BSc, MSc (Public Health Science)

Institute of Preventive Medicine, Øster Søgade 18, DK-1357 Copenhagen K, Denmark. E-mail: tfm@si-folkesundheddk

Alcohol is one of the leading risk factors and is responsible for a substantial part of the global disease burden. The aim of this presentation is to give an overview of predictors that increase the risk of alcohol use disorders. The results are based on a large 
prospective study, the Copenhagen City Heart Study, which is an ongoing series of studies conducted in the Danish population, initiated in 1976. An age-stratified sample of 19,698 men and women aged 20 to 93 years who lived in the Copenhagen area were randomly drawn from the Central Population Register, using the unique person identification number and invited by letter to answer self-administered questionnaires. The study population was linked to three different registers in order to determine Alcohol Use Disorders.

The presentation will describe the significant findings and describe how different social factors are associated with an increased risk of alcohol use disorders.

Clinical holistic medicine: Factors influencing the therapeutic decision-making. From academic knowledge to emotional intelligence and spiritual 'crazy' wisdom

Soren Ventegodt, MD, MMedSci, EU-MSc and Joav Merrick, MD, MMedSci, DMSci

Quality-of-Life Research Center, Nordic School of Holistic Medicine \& Research Clinic for Holistic Medicine, Copenhagen, Denmark; E-mail: ventegodi@ livskvalitet.org; and National Institute of Child Health and Human Development, Jerusalem, Israel; e-mail: jmerrick@internet-zahav.net

Scientific holistic medicine is built on holistic medical theory, therapeutic and ethical principles. The rationale is that the therapist can take the patient into a state of salutogenesis, or existential healing, using his skills and knowledge. But how ever much we want to make therapy a science it remains partly an art, and the more developed the therapist becomes, the more of his/her decisions will be based on intuition, feeling and even inspiration that is more based on love and human concern and other spiritual motivations than on mental reason and rationality in a simple sense of the word. Surprisingly, the more the therapist dares to be himself and do whatever is felt necessary in the therapeutic session, the more will he be visible, trustworthy and lovable to his patient, and the more effective will the therapy be. So the dry, distant, and controlled personality of the "academically trained expert-helper" seems to be a most serious hindrance for efficient therapy; the therapist who on the other hand devotes to the therapy not only his mind and knowledge but his full presence including emotions, body and sexuality, and even his spiritual and divine aspects of being, will be able to fully engage his patient in the therapeutic process and thus be able to take him into existential healing. The provocative and paradoxical medieval western concept of the "truth telling clown" or the eastern concepts of "crazy wisdom" and "holy madness" seems highly relevant here. The problem is how we can ethically justify this kind of highly 'irrational' therapeutic behavior in the rational setting, i.e. on a medical institution; we argue here that holistic therapy has a very high success rate and is doing no harm to the patient, and encourage therapists, psychiatrists, psy'chologist and other academically trained 'helpers' to constantly measure their own success-rate and experiment with a more holistic approach to therapy allowing emotional and spiritual intelligence to come into use also, as a most vital and important supplement to the use of mental IQ and reductionistic, scientific principles. In the end it is the love that cures the patient's existence in holistic therapy, not tools, rules or procedures however smart. Love must be allowed to take whatever form it needs to make its miracle; and often these forms seem ridiculous and incomprehensible for the rational mind. This paper discusses many important factors that influence clinical holistic decision-making. Sexuality could, as many psycho-analysts from Freud to Reich and Searles have believed, be the most healing power that exists and also the most difficult for the mind to comprehend and thus the most "crazy-wise" tool of therapy.

\section{Acupressure used as a pre-birth treatment at full} term gestation

Katie Moriarty, PhD, CNM, APN, RN and Dorie Schwertz, PhD, FAAN, RN

Advocate Illinois Masonic Medical Center, $3048 \mathrm{~N}$. Wilton, Nurse-Midwifery Service, 3rd Floor, Chicago, IL, 60657 USA. E-mail: moriartykam(a.hotmail.com and College of Nursing, Room 746, University of Illinois at Chicago, 875 S. Damen Avenue, Chicago, IL 606127350 USA. E-mail: schwertz@uic.edu

National vital statistics report a current induction of labor (IOL) rate of $20.6 \%$. The WHO recommends less than $10 \%$ rate. Women that spontaneously labor versus having an IOL have decreased morbidity. Spontaneous labor requires a balance of multiple complementary and parallel mediators. Some of these mediators are the same as those elicited by the stress response. Acupressure is thought to reduce the stress response. Acupressure pre-birth treatments (APR PB-Tx) are utilized at term gestation to "balance" mediators and encourage cervical ripening and initiation of labor. Methods: A psycho-neuro-endocrinology frame-work was utilized in this one group $(n=25)$, repeated measures design to examine psychophysiologic responses to a one time, 30 min APR PB-Tx administered to pregnant subjects during 
their 39th week of gestation. Categorical variables were analyzed by descriptive statistics or Chi square and continuous variables by repeated measures ANOVA or paired t-tests. Results: APR PB-Tx decreased or had no effect on the maternal stress response as indicated by a pre- to post-PB-Tx decrease in maternal heart rate and diastolic blood pressure (other vital signs remained unchanged). Salivary $\alpha$-amylase activity and salivary cortisol levels did not change from immediately pre- to post-APR PB-Tx periods. APR PB-Tx decreased maternal anxiety as measured by State-Anxiety and visual analogue scale. Increased uterine irritability yet no significant increase of frequency/duration of contractions was noted during the protocol. Fetal heart rate variables were reassuring and stable throughout the protocol. Response to a post PB-Tx maternal questionnaire revealed perceived qualitative increases in contractions and fetal activity during the APR. Subjects reported feeling relaxed and empowered by the treatment. Conclusions: A noninvasive approach that could impact endogenous signals to encourage labor or alter signals that may impede labor would have multiple advantages. Future studies will incorporate a control/ comparison group to examine efficacy of APR PP-Tx reducing $\mathrm{IOL}$ rates.

A phase I study of high-dose IV vitamin C treatment in patients with solid tumors

Christopher M Stephenson', DO, Christopher G Lis', MPH, Robert D. Levin', MD, Candi Pfeiffer', BSN, Jessica Kapustin', BSN and Thomas Spector ${ }^{2}$, PhD

'Cancer Treatment Centers of America (CTCA) at Midwestern Regional Medical Center, Zion, IL, USA. ${ }^{2}$ Spector Consulting Services, Durham, NC, USA.

Correspondence: Christopher G Lis, Vice President, Research and Development, Cancer Treatment Centers of Americu and Executive Director, CTCA-University of Illinois at Chicago School of Public Health, Clinical Epidemiology Fellowship Program, 2610 N. Sheridan Road, Zion,IL 60099, USA. E-mail: christopher.lis@ctcahope.com. Web: www.cancercenter.com

In October 2006, CTCA (Cancer Treatment Center of America) initiated an FDA-approved Phase I study of intravenous vitamin $C$ in patients with solid tumors and no available treatment. High doses of vitamin $\mathrm{C}$ are being used to achieve blood levels reported to be toxic to tumor cells. Cohorts of three patients receive vitamin $C$ infusions on 4 consecutive days/week for 4 consecutive weeks. Patients may then continue on the protocol with two infusions/week. Doses are incrementally increased in future cohorts until either the MTD is reached, or sustainable high blood levels are obtained. The infusion rate is $1 \mathrm{~g}$ vitamin $\mathrm{C} / \mathrm{min}$. We are determining the safety, tolerability, appropriate dose, pharmacokinetic (PK) profile of vitamin $C$, and the patient's quality-of-life status. We are also assessing tumor burden for preliminary indications of anti-cancer activity. The PK values were obtained for the first two cohorts treated with 30 and $50 \mathrm{~g} / \mathrm{m}^{2}$ vitamin C, respectively. Vitamin $\mathrm{C}$ was eliminated form patient's blood in a simple first-order exponential decay with a half-life of about $2 \mathrm{hr}$. The half-life, $\mathrm{C}_{\max }$, clearance, and AUC $\infty$ of vitamin $C$ in each patient did not systematically change during their 4-weeks of treatment. The half-life and clearance of vitamin $\mathrm{C}$ remained fairly constant for all patients of both cohorts, while the $\mathrm{C}_{\max }(23$ and $33 \mathrm{mM}$ ) and $\mathrm{AUC} \infty$ (74 and $124 \mathrm{hr} \mathrm{mM}$ ) increased proportionately with the dose. Vitamin $\mathrm{C}$ did not accumulate during consecutive treatments. We will discuss other preliminary findings as well as adjustments to the amount of calcium and magnesium included with the $70 \mathrm{~g} / \mathrm{m}^{2}$ vitamin $C$ dose for the third cohort. This clinical trial remains open for eligible patients. The results should provide the optimal dose and motivation for a subsequent Phase II clinical trial.

Nutritional supplements as a form of sports doping in the adolescent athlete

Donald E Greydanus, MD

Michigan State University College of Human Medicine, East Lansing and Kalamazoo, Michigan, USA. E-mail: greydanus@kcms.msu.edu

For centuries athletes have used various drug mixtures in an attempt to improve their athletic performance. Though anabolic steroids have become better known to the public in recent times because of their consumption by some professional athletes, Nutritional Supplements have also become popular with youth seeking to become better athletes and hoping they are ergogenic agents. The term, sports doping, has been applied to this practice. Ergogenic" comes from the Greek word, érgon (to work) and gennan (to produce) and when applied to a chemical or drug, implies that the consumer will be able to "work" better or be a winning athlete. The word "doping" comes from the Dutch word, dop, referring to a mixture of opium given to stimulate racing horses. This discussion reviews some of these proposed agents, including. antioxidants, caffeine; calcium; carnitine, chromium; creatine, protein and amino acids. Creatine is an essential amino acid synthesized from arginine and 
glycine in the liver, pancreas and kidneys. Over $\$ 200$ million sales are noted annually, though it is naturally available in milk, meat, fish and other foods. A loading dose of $20 \mathrm{gm}$ per day for one week is often used, followed by 10-15 gm per day for maintenance. There may be a 5-15\% improvement in short-term, repetitive/intermittent, high intensity exercise--including power-related sports. There is no improvement with long-term endurance activities--perhaps even some harm. Increased muscle mass may result, due to fluid retention versus increased protein synthesis. An increase of 0.7 to $3 \mathrm{~kg}$ in one month has been reported; a weight gain can be maintained on 5 grams per day of creatine during a 10 week period of detraining and maintained four weeks after its use is stopped. Though creatine is considered "safe", there are side-effects and risks: weight gain, muscle cramps, strains, dehydration in hot/humid weather, renal function deterioration, suppression of endogenous synthesis, and cardiac muscle hypertrophy. Long term (ie, over 1 year) effects are unknown and no studies noted in children or adolescents. The use of protein and amino acid supplen.ents has sparked a long-lasting debate regarding their efficacy in sports performance. Though athletes do need more protein than their non-exercising peers, most athletes take enough protein from their diets and probably do not benefit from extra protein. If the teen has a deficient diet, supplements may help. Wrestlers, gymnasts, dancers and others may have poorly balanced diets and/or seek to lower their weights. Evaporated milk and protein powder (egg or soy) are low cost supplements that can be recommended. The use of branched-chain amino acids and others which may increase the production of growth hormone has not been proven to be of benefit to adolescent athletes. Other supplements will be discussed.

Clinical holistic medicine (mindful short term psychodynamic psychotherapy complimented with bodywork) in the treatment of mental health problems

Søren Ventegodt ${ }^{1,2,3,45}$, Isack Kandel ${ }^{6}$ and Joav Merrick ${ }^{7,8.9}$ 'Quality of Life Research Center, Teglgärdstrade 4-8, DK-1452 Copenhagen K, Denmark; ${ }^{2}$ Research Clinic for Holistic Medicine and ${ }^{3}$ Nordic School of Holistic Medicine, Copenhagen, Denmark; 'Scandinavian Foundation for Holistic Medicine, Sandrika, Norway; ${ }^{5}$ Interuniversity College, Graz, Austria; ${ }^{6}$ Faculty of Social Sciences, Dept. of Behovioral Sciences, Ariel University Center, Samaria, Ariel, Israel; ' National Institute of Child Health and Human Development, ${ }^{8}$ Office of the
Medical Director, Division for Mental Retardation, Ministry of Social Affairs, Jerusalem, Israel; 'Kentucky Children's Hospital, University of Kentucky, Lexington, USA.E-Mail:ventegodt@livskvalitet.org

Clinical holistic medicine (CHM) has developed into a system that can cure somatoform and psychoform dissociation and thus cure even the most severely mentally ill patients. Schizophrenia can be understood as the most extreme state of "no sense of coherence"; to heal the patient recovery of the sense of coherence through Antonovsky-salutogenesis is mandatory. CHMtherapy supports the patient through a series of emotionally challenging, existential, healing crisis. Through the process of feeling old repressed emotions, understanding life and self, and finally letting go of negative beliefs and delusions, the patient's sense of coherence and mental health is recovered. The Bleuler's triple condition of autism, disturbed thoughts, and disturbed emotions that characterizes the schizophrenic patient can be understood as arising from the early defense of splitting, caused by negative learning from painful childhood traumas that made the patient loss sense of coherence and withdraw from social contact. Self-insight gained though the therapy allows the patients to take their bodily, mental and spiritual talents into use. In the end of therapy the patients are once again living a life of high quality centered on the lifemission; they relate to other people in a way that systematically creates value. There are a number of challenges meeting the therapist working with schizophrenic and psychotic patients, from the potential risk of experiencing patient's violence to the obligation to contain the most difficult and embarrassing of feelings, when the emotional and often also sexual content of the patient's unconsciousness becomes explicit. Many schizophrenic patients have severe psychosexual traumas from rape and incest that must be integrated. Development of patients ability to love, understand and enjoy life are mandatory.

Doctor-patient relationships in integrative medicine: Contemporary social trends

Sandra Grace ${ }^{1}$, MScChiro (Res), DC, DO and Joy Higgs ${ }^{2}$ AM, BSc, MHPEd, PhD

'The University of Sydney, Australia, ${ }^{2}$ The Education for Practice Institute, Charles Sturt University, Australia Correspondence: Sandra Grace, Education for Practice Institute, Charles Sturt University, 16 Masons Drive, North Parramatta NSW 2151 Australia. E-mail: sgrace@ csu.edu.au; Website: u'ww.csu.edu.au/division/landt/ep/ 
The increasing use of complementary and alternative medicine (CAM) in developed countries has been attributed to general societal changes rather than any inherent problems in conventional medicine. Holding post-modern values has been specifically identified as a predictor of CAM use. Integrative medicine which combines conventional medicine and CAM is an emerging model of primary health care in Australia. The aim of this study was to examine the effect of postmodern values on relationships between practitioners of integrative medicine and their patients. Method: Case studies of three integrative health clinics examined practitioners' and clients' perceptions of doctor-patient relationships. Data were collected using direct observation for ten days in each clinic and semistructured interviews with practitioners and patients. By reading and re-reading texts, derived from interview transcripts and field notes, common themes and then meta-themes emerged from the data. Results: Although patients of integrative medicine represented diverse social groups and disease profiles, they fell predominantly into two categories: those seeking management of chronic health conditions, and those seeking health promotion and illness prevention. Post-modern values influenced the way patients approached consultations. They did not bring an expectation that they would receive prescriptive regimens. They regarded consultations as opportunities for gathering information or advice or for monitoring their health. Many patients were active partners in consultations, contributing knowledge about research and treatments from sources such as internet, support groups, family and friends. Shared decision making in a nonjudgmental atmosphere was a key feature. Practitioners' teaching and advisory roles had evolved from pedagogic to heutagogic, i.e. practitioners were a resource patients used for information about health care and not necessarily a privileged one. Discussion: Integrative medicine is authentically client-centered care. It is essentially the pursuit of wider choice and better outcomes in health care and aligns with contemporary aspirations in society generally towards synthesis and holism.

Pulsed magnetic field effects on pain and other symptoms in rheumatoid arthritis Cheryl Bourguignon, PhD, RN and Ann G Taylor, EdD, RN, FAAN

Center for the Study of Complementary and Alternative Therapies, University of Virginia, Charlottesville, USA Correspondence: Cheryl Bourguignon, PhD, RN, Assoc. Professor and Statistician, Center for the Study of
Complementary \& Alternative Therapies, University of Virginia, P.O. Box 800905, Charlottesville, VA 229080905 USA. E-mail: cb2n@virginia.edu

Objectives: To investigate pulsed magnetic field (PMF) effects on pain, other symptoms, and functional status in women with rheumatoid arthritis (RA). Methods: The 12-week pilot study used a randomized 3group (PMF, sham, usual care-UC) design, with PMF and sham groups double-blinded. The sample consisted of 52 postmenopausal women with an average age of $59.9 \pm$ 7.5 and duration of RA of $11.6 \pm 11.7$ years. The PMF and sham groups lay on full body pads twice a day, for 8 min each time. All participants remained on their usual care regimes. The instruments, numeric rating scale (010) for average pain, Lee's Fatigue Inventory, depression (CESD), and Health Assessment Questionnaire (HAQ), were completed by participants at baseline and weeks 1-8 and 12. Multilevel modeling was used to analyze differences in symptoms over time between groups. Results: The PMF group had different slopes for pain, fatigue, and functional status (respective trends, $p=.060, p=.056$, $p=059$ ) compared with sham or UC groups. Pain was a time-varying covariate in the analyses of fatigue and functional status. Pain appeared to decrease the most between weeks 8 and 12. Depression did not differ over time between the groups. Conclusions: Pain, fatigue, and functional status improved over time in the PMF group compared to the other groups, while depression did not. A longer study should be conducted to determine if pain continues to decrease in the PMF group compared to other groups. Acknowledgment: The project was supported by Grant Numbers: 1-R21-AT001469-01 and 5K30-AT000060 from National Center for Complementary and Alternative Medicine (NCCAM). Its contents are solely the responsibility of the authors and do not necessarily represent the official views of NCCAM, NIH.

The ontological concept of the person: Does bioethics need it?

Kamilla Bargiel-Matusiewicz MA, PhD and Leslaw Niebroj MA, PhD

Faculty of Psychology, University of Warsaw, 5/7 Stawki Str, 00-183 Warsaw; (E-mail: kmatusiewicz@op.pl) and Dept. of Philosophy \& Pedagogy, Medical University of Silesia, 12 Medyków Str, 40-752 Katowice; Poland

The four-principles approach to bioethics, also known as principlism, is commonly considered the mainstream of bioethics. Although originally it was assumed that all moral dilemmas in medicine were to be explained and resolved in the light of four, equal, mid-level and prima 
facie principles, nowadays the principle for respect for patient's autonomy plays the central as well as fundamental role. Through or together with this emphasis on autonomy, the very understanding of the concept of 'human person' has profoundly changed. The human person is considered to be an 'autonomous subject' rather than 'embodied being'. It should be emphasized however that this, based exclusively on autonomy, purely functional concept of person is not without its problems. Among them, the two seems to be the crucial ones, i.e. moral status of non-autonomous human beings (e.g. newborns) and the problem of the continuity of identity of human person, which seems to have a particular importance in the ethical debate over the use of so-called 'advance directives' or 'living wills'. The purpose of this presentation is to study whether the functional concept of human person is efficient in resolving these problems or it is necessary to recall to the so called ontological concept of human person. The concept of "common morality" is discussed. It is argued that the set of common morality norms, which seems to be indicated as an ultimate justification of moral norms in medical ethics in the 5th editions of Beauchamp and Childress landmark work "Principles of Biomedical Ethics", needs to be grounded in set of ontological assumptions. The presentation will argue that the ontological concept of human person should be listed among the most important convictions belonging to 'common ontology'.

Breaking the orgasm-barrier by re-parenting, genital acceptance and clitoral stimulation

Pia Struck and Soren Ventegodt

European Orgasm Academy, Copenhagen and Quality-of-

Life Research Center, Nordic School of Holistic Medicine and Research Clinic for Holistic Medicine, Copenhagen, Denmark.E-mail: pia@seksualterapi.dk

Objective: To test the Betty Dodson method of breaking the female orgasm-barrier in chronic an-orgasmic women using re-parenting, genital acceptance and direct, sexual, clitoral stimulation with the Dodson Vibrator. Design and setting: Study with holistic, sexologic, manual therapeutic intervention. The patients received $3 \times 5$ hours of group therapy and each paid 500EURO for participation in the treatment program. Participants: 500 chronically anorgasmic female patients between 18 and 88 years old participating in the "Betty Dodson orgasm course for anorgasmi: women". In average the patients were 35 years old, had not had an orgasm for 20 years; $25 \%$ of patients had never experienced an orgasm before. Main outcome measures: Subjective experience of having an orgasm in combination with therapist observation of the patient having orgasm judged from "objective orgasmic behavior": impression of altered state of consciousness, involuntary, rhythmic contractions of the pelvic and other musculature, vaginal and anal contractions, in combination with induction of well-being and contentment. Results: On 100 courses with 3-6 participants in each and 500 patients in total only one course in three had a patient that did not get orgasm ( 35 patients, or $7 \%$ ). 465 patients ( $93 \%$ of the patients) had orgasm during therapy witnessed by the therapist. Postmenopausal women are as able to get orgasm as fertile women and so are woman who never had an orgasm. The method had no side or adverse effects. Conclusions: The female orgasm barrier seems to be caused primarily by parent's lack of acceptance of the girl's genitals and sexuality. Direct, sexual, clitoral stimulation is a highly effective therapeutic tool for solving the problem of female anorgasmia. Therapeutic elements seem to be re-parenting, intent of acceptance, acceptance through touch, and a direct confrontation of the shame, guilt and other negative feelings associated with genitals and sexuality. Holistic, sexologic, manual therapy is extremely efficient; with this tool sexologists are able to help practically all female patients with problems related to orgasm and desire, also when normal conversational therapy and bodywork cannot help.

Is there a holistic approach around the issue of persons with intellectual disability at home, in community setting, or in residential care?

Isack Kandel, MA, PhD and Joav Merrick, MD, MMedSci, DMSc

Faculty of Social Sciences, Dept. of Behavioral Sciences, Ariel University Center of Samaria, Ariel, Israel (E-mail: kandelii@zahav.net.il) and National Institute of Child Health and Human Development, Office of the Medical Director, Division for Mental Retardation, Ministry of Social Affairs, Jerusalem and Kentucky Children's Hospital, University of Kentucky, Lexington, USA (E-Mail: imerrick@internet-zahav.net)

The parents of disabled children at one time or another face the question of keeping the child at home or placement in community or residential care settings. The choice between the two alternatives resides with the parents and various factors influence their decision. Several researchers have identified these factors, which included child related parameters, family and parental attitudes, the influence of the social environment and the external assistance provided to the family. The 
recent much published case of the nine year old girl Ashley from Seattle in the USA focused on the issues of quality of life for the child, the family and how far professional intervention can be pursued. From several studies conducted in Israel we have attempted to isolate the main factors involved in the parental decision to keep th: child at home or place the disabled child. Our results indicated that parental related factors were the dominant factors. Guilt feelings served as the main factor for parents to delay placement in residential care.

\section{Psychoactive drugs and healing}

Wendy Chapkis

Dept. of Sociology, University of Southern Maine, 96 Falmouth St. P.O. Box 9300 Portland, MIE 04104, USA. E-mail: chapkis@usm.maine.edu

The consciousness-altering properties of plants such as cannabis are generally understood by prohibitionist policy makers as a critical impediment to the drug's designation as a medicine. Indeed, for many, the claim that cannabis is of any therapeutic value is no more that a "ruse" employed not for the benefit of the dying but, rather, for those dying to get high. In response, many medical marijuana advocates downplay the drug's popular psychoactive effects, instead choosing to emphasize the role marijuana can play in managing pain, calming chemo-therapy related nausea, enhancing appetite in patients suffering from AIDS-wasting, relieving muscle spasticity associated with MS, reducing intraocular pressure for glaucoma suffers, or controlling seizure activity among epileptics. It is as if the "high" which makes the drug an attractive recreational substance, either disappears with medical use or is nothing more than a trivial side-effect unrelated to the plant's therapeutic value. But in-depth, semi-structured interviews with 42 patients affiliated with one Californiabased patient-caregiver cooperative, the Wo/Men's Alliance for Medical Marijuana (WAMM), suggest that, for many patients, the consciousness-altering properties may be an important part of the plant's therapeutic value.

The relationship between motor and oral-motor development in full-term and preterm infants Helena Törölä, MA, Matti Lehtihalmes, PhL, Merja Luukinen, PT, Anneli Yliherva, PhD and Päivi Olsén, MD Dept. of Finnish, Information Sstudies and Logopedics, University of Oulu, Pediatric Clinic, Oulu University Hospital, Dept. of Physiatry, Oulu University Hospital, and Dept. of Child Neurology, Oulu University Hospital, Oulu, Finland.E-Mail: risto.torola@baanamail.fi
Background: The development of oral-motor skills seems to be closely tied to overall physical development. In general the fine motor skills are dependent of gross motor development, although the causal or temporal development of these fields in relation to each other is not well known. Objective: The aim of this qualitative and descriptive study is to follow the gross motor and oral-motor development and their interrelationship in full-term and preterm infants more detailed, which could help to plan and define the time when to start the intervention. Subjects: There were 11 full-term infants and 19 preterm infants in the sample. The preterm infants were born with a birth weight less than $1000 \mathrm{~g}$ (range $670-1020 \mathrm{~g}$ ) and at the average gestational age of 27 weeks (range $23-30$ weeks). All children were born at the University hospital of Oulu. Methods: The follow-up of the full-term infants started after birth before discharge and that of the preterm infants at the age of 37 weeks gestational age. All infants were videotaped every second week up to the age of three months and ever since once in a month until they could chew their food, drink from the cup, take first steps and produce the first word. The motor development was analyzed using the Alberta Infant Motor Scale (AIMS), the muscle tone using the modified Ashworth scale of muscle spasticity, the oralmotor functions using the Neonatal Oral Motor Assessment Scale (NOMAS) and Oral motor patterns checklist (Beckman modified). In addition, the vocalizing of the infants was analyzed acoustically using a scales based on scientific literature.

Vocabulary and mean length of utterance of 2-yearold preterm children measured by MacArthur Communicative Development Inventory (MCDI) in ACG- and HC-groups

Annelie Yliherva ${ }^{1}$, Laura Kuukasjärvi', Marjut Ylisuvanto', Minna Viitaniemi, Outi Peltoniemi ${ }^{2}$ and Mikko Hallman ${ }^{2}$

${ }^{\prime}$ Dept. of Finnish Information Studies and Logopedics and ${ }^{2}$ Dept. of Pediatrics, University of Oulu, Oulu, Finland Correspondence: Anneli Yliherva, PhD., professor, Faculty of Humanities, Box 1000, 90014 University of Oulu, Finland, tel: +358-8-553 3374, e-mail: anneli. yliherva@oulu.fi

The aim of the study is to find out if antenatal corticosteroids (ACG) given to a mother or hydrocortisone (HC) treatment decrease the incidence of typical lung disease, BPD (brochopulmonary dysplasia) in preterm children. BPD has been reported to be a risk factor for 
preterm children's speech and language development. In the present study vocabulary and mean length of utterance are studied in both treatment groups. Material and methods: The follow-up study was performed when the children were at two years' postnatal age. At the University Hospital of Oulu the speech and language development was studied in 21 preterm children in HCtrial (total $n=25$ ) and 34 in ACG-trial groups (total $\mathrm{n}=59$ ). The preterm children were randomized in treatment and control groups. Speech and language therapist studied the children's speech and language development using MCDI, Reynell III, Symbolic Play Test, and also a free play situation which was videotaped. The information on family background factors and a child's development during postnatal period was gathered using a questionnaire. Also a pediatrician, child neurologist and psychologist did their examinations. Results: All the children in HC- and ACG-groups have been studied. According to the preliminary results the speech development in HCgroup and control group (placebo) does not clearly differ from each other when using parental questionnaire MCDI. Anyway the analyses of HC- and ACGgroup are ongoing. Conclusion: The analyses are in process, and more detailed information will be available in the future. Both groups will be compared with their matched full-term pairs which could also give more information of treatment effect on speech development.

\footnotetext{
Flaxseed and phytoestrogen lignans for holistic health and medicine

Lilian U Thompson, PhD

Dept. of Nutritional Sciences, Faculty of Medicine, University of Toronto, 150 College St, Toronto, Ontario MSS 3E2, Canada.E-mail: lilian.thompson@utoronto.ca Phytoestrogens such as the isoflavones in soy, and lignans the richest in flaxseed have weak estrogenic and antiestrogenic properties; therefore they may influence hormone related diseases or conditions such as breast cancer, osteoporosis and menopausal symptoms. My laboratory focused on flaxseed, which is also exceptionally rich in $\alpha$-linolenic acid, an $n-3$ fatty acid with potential anticancer effects. This presentation will summarize our studies over 20 years on the effects of flaxseed on breast cancer and, as a holistic approach to health and medicine, also its effect on bone health, menopausal symptoms and safety. Studies were initially conducted in animal models and later in breast cancer patients and menopausal women. In carcinogen-treated
}

rats, flaxseed reduced the tumor incidence, number and size when fed at the initiation, promotion or progression stages of carcinogenesis. In athymic mice with xenografts of estrogen receptor negative (ER-) human breast cancer, flaxseed caused the tumor size to regress and reduced metastasis. In athymic mice with ER+ human breast cancer xenografts, tumor growth was suppressed due to a reduction in tumor-cell proliferation and angiogenesis and increased apoptosis through the modulation of ER and growth factor-signaling pathways. Combining flaxseed with soy or breast cancer drug tamoxifen was more effective in reducing breast tumor growth than with soy or tamoxifen alone. In double blind placebo controlled randomized trial with breast cancer patients, daily consumption of $25 \mathrm{~g}$ flaxseed led to significant reductions in tumor cell proliferation and HER2 expression and increase in apoptosis, indicating better prognosis, in agreement with animal studies. No significant reduction on bone status or effect on menopausal symptoms was observed. No adverse effects were seen in both animal and clinical trials. In conclusion, flaxseed and its lignans can play a role in the prevention and treatment of breast cancer while causing no adverse effects on other body tissues.

What do college instructors and counselors know about the effectiveness of CAM to treat trauma?

Mary Pritchard, PhD, Patt Elison-Bowers, PhD, Phares Book, PsyD and Bobbie Birdsall, PhD

Dept. of Psychology, Boise State University, 1910 University Drive Boise, Idaho 83725-1715, USA.

E-mail: marypritchard@boisestate.edu Website: http:/ /psych.boisestate.edu/mpritchard/index.htm

A recent article in the Journal of the American Medical Association reported that mental health issues in veterans returning from Iraq and Afghanistan have been greatly underestimated by the Department of Defense (DoD) (Milliken, Auchterlonie and Hoge, 2007). Current estimates of the percentage of returning veterans that require mental health treatment services have ranged from $20.3 \%$ to $42.4 \%$, depending on the survey in question. Yet, a recent task force mandated by the United States Congress reported that the existing mental health facilities funded by DoD were overburdened, understaffed, and under-resourced, meaning that many veterans are falling through the cracks and seeking help elsewhere, such as in private therapy sessions. As private therapists are being called on more and more often to help clients suffering with war-related trauma it is becoming increasingly important to assess how much therapists 
know about trauma and effective ways to treat it, including more traditional approaches, such as medication and group therapy, as well as more alternative approaches, such as meditation and integrative restoration. Similarly, as more veterans are taking advantage of the GI bill upon completion of their service, many college instructors are finding themselves dealing with trauma-induced episodes in the classroom. Thus, it is also important to assess what college instructors know about trauma and its treatment. The present study assessed just that. We surveyed college instructors and private therapists to determine what they knew about trauma and its treatment, as well as their personal experiences with trauma victims in their offices/classrooms. Implications for improving treatment will be discussed.

The presenting complaints of pediatric patients to chiropractors: results from a practice-based research program.

Joel Alcantara, BSc, DC ${ }^{1}$, Jeanne Ohm, $\mathrm{DC}^{2}$ and Derek Kunz, BS ${ }^{3}$

'Research Director, International Chiropractic Pediatric Association, Media, PA, USA (dr_jalcantara@yahoo. com), ${ }^{2}$ Private Practice of Chiropractic, Media, PA, USA and ${ }^{3}$ Research Associate, International Chiropractic Pediatric Association, Media, PA, USA

At the turn of the century, it was estimated that approximately $\mathbf{3 0}$ million pediatric visits were made to chiropractors in 1997 in the USA. The cost of these office visits were also estimated at \$1billion of which $\$ 510$ million was paid out-of-pocket by parents. Indications are that these visits continue to increase as indicated by the most recent 2003 Job Analysis of Chiropractic by the National Board of Chiropractic Examiners (NBCE). The NBCE estimated an $8.5 \%$ increase in the percentage of chiropractic patients less than 17 years of age since their 1991 survey. From a general perspective, studies continue to document the wide range of complementary and alternative medicine (CAM) for a variety of conditions in children. Studies have lent support to this notion and point to the popularity of chiropractic care for children. Chiropractic was founded on a holistic and vitalistic approach to patient care. With growing concerns to adverse drug reactions and the need for a more conservative approach to the care of their children, parents are opting for chiropractic care. Despite the ever growing popularity of pediatric chiropractic, few studies, if any, report on the prevalence on the kinds and types (or reasons) of conditions presenting to chiropractic practices. To address this deficit and contribute to evidence-based practice, a study was undertaken to determine the types of conditions and reasons for parents to bring their children to chiropractors participating in a practicebased research network. In addition to characterizing geographic information (i.e., gender and age) of the parents and their children, we found that musculoskeletal conditions comprised a large percentage of the primary and secondary complaints in addition to the common diseases of childhood such as otitis media, enuresis, colic, etc. Based on our findings, we conclude that chiropractors address musculoskeletal conditions in the care of children as they do in adults. However, this is in addition to the non-musculoskeletal conditions of childhood. Furthermore, the musculo-skeletal conditions addressed are of the type unlike those presented by adults lending further support to the unique considerations for this special patient population.

Pranayama, the Power of Breath (Workshop demonstration)

Ram B Singh, MD

Halberg Hospital and Research Institute, Moradabad, India.E-mail: icn2005@sancharnet.in or icn2008@ mickyonline.com

Patanjali, (600AD), the codifier of yoga science, proposed that the control of prana (mind) is the regulation of inhalation and exhalation. This is accomplished by eliminating the pause between inhalation and exhalation or expending it by retention. It regulates the motion of the lungs, resulting into control of heart and vagus nerve. The science of pranayama is thus intimately connected with the autonomic nervous system and brings its functions under conscious couit ol via breathing patterns and movements of diaphragm and lungs. The nasal tissue is erectile, similar to sex organs in men and women, which is very sensitive to breath. Control of breath constitutes an obvious starting point toward attainment of control of autonomic nervous system which appears to have beneficial effects on the functions of omental adipocytes, brain, heart, lungs, liver and kidney functions. Left nostril, diaphragm and stomach are supplied by the vagus nerve, which may influence pituitary function, hypothalamus, pineal gland and suprachiasmatic nucleus. Studies conducted in Italy have shown that verbalization of mantras like Oem Namasway Namah can decrease breathing rate, due to increased vagal activity, resulting into increased nitric oxide release when the breathing rate is brought down 
to less than $10 / \mathrm{min}$.In few subjects, we have demonstrated increased heart rate variability by verbalization of Ram, Rama, Rama. Common methods for pranayama: Anulome velome: Sit straight and do not move shoulder or neck. (1) Close both the eyes and concentrate on inspiration and expiration, alternately from each nostril, starting from left nostril. (2) Take deep inspiration slowly followed by a pause of few seconds, then do complete expiration from the other nostril, while one nostril is closed by the thumb. All the steps of breathing, "in and out" should be performed very gently without any strain. Kapal Bhati: Exhale or expire the breath by moving diaphragm and abdominal muscles during inspiration and expiration. During expiration, the muscle of abdomen moves outside and during inspiration the abdomen moves up. Both Kapal bhati and Anulome and Velome should be conducted preferajly with empty stomach for maximum beneficial effects. Pranayams could be practiced either on bed or while sitting on chair. Regular practice of pranayams may have beneficial effects on obesity, diabetes, hypertension, insulin resistance, heart attacks, asthma and bronchitis $(n=123)$, allergies, memory dysfunction and aging.

\section{Integrative solutions in prostate cancer}

Jim Roach, MD

Midway Center for Integrative Medicine, 129 South Winter Street Midway, KY 40347-0277, USA. E-mail: JPRoach@aol.com

A wealth of research has revealed how integrative interventions can transform prostate cancer care. Fundamental dietary modifications, the role of spirituality, and impact of the patient's environment will be addressed. What are important pitfalls to surgery and radiation approaches? What blood tests are important to perform and monitor during treatment? What nutrients are revolutionizing care for these patients, and how do they work? What is the outcome of chemotherapy combined with nutrient support? Case studies will demonstrate the effective application of integrative approaches.

Outcast youngsters: Psychosocial conditions of social exclusion risk

Agnieszka Wilczynska-Kwiatek, MA, PdD

Institute of Social and Environmental Psychology, Dept. of Psy'chology and Pedagogics, University of Silesia, 53 Grazynskiego Str, Katowice 40-086, Poland. E-mail: anvkwiatek@op.pl

The reasons for social exclusion risk related to youngsters prone to crime are both psychological and social in nature. An overview of the Polish and European publications reveals that researchers tend to focus more on the social rather than psychological reasons and consequences of this phenomenon. It needs to be emphasized, however, that genuine assistance or treatment of youth's disturbed behavior requires both sociotherapeutic as well as a professional psychotherapeutic approach. The notion of youth at risk concerns a group of young people who, during childhood and adolescence, encounter in their local environment a number of situations which they are unable to cope with. When a maturing youngster lacks constructive patterns of handling difficulties, they often take decisions impairing their development. In early adolescence the increasing force of impulses combined with a relatively weak ego cause that teenagers experiment with other individuals in new situations, commence premature sex life, use aggression, try drugs and other substances, give up school and even attempt suicidal actions. As it turns out, a poor and dysfunctional family is unable to fulfill the child's basic needs or offer any support to them while going through difficult or crucial developmental moments. A maturing adolescent perceives their parents in a hostile light, sees them as disappointing and inadequate, remains in conflict with them, and at the same time feels lonely and isolated as well as suffers owing to the aforesaid lack of support. Disturbed behavior occurring in this period is often related to depression manifested by aggression. A fairly common notion used with reference to adolescents, especially boys, is the so-called atypical depression characterized by the absence of external symptoms of sadness and presence of intensified resistance, physical aggression and dangerous conduct. In my research-based presentation I attempt to show indicators and predictors of youth social exclusion risk as well as discuss methods of preventing this threat in Polish and European conditions.

Integrating CAM into a health sciences curriculum Geza Bruckner, PhD, Janice Kuperstein PT, MSEd and David Fahringer, PA-C, MSPH

Dept. of Clinical Sciences/Division of Clinical Nutrition, College of Health Sciences, University of Kentucky, Lexington, KY 40536 USA. E-mail: gbruckn@email.uky.edu By its very nature, Complementary and Alternative Medicine (CAM) is both holistic and interdisciplinary. However introduction of the topic, if done at all, is traditionally done in the standard silos of single 
disciplines. In developing interdisciplinary CAM content for seven healthcare disciplines in a College of Health Sciences, the major barrier identified was the divergent class schedules. The most efficient, cost effective and flexible plan to deliver CAM content into all disciplines was to develop a web-based course that could be delivered in a team taught manner. The guidelines for the course content were: 1 ) build bridges across disciplines within and outside the college, 2) introduce evidence-based integrative care, 3) select alternative modalities for presentation that are widely used by patients and are evidence based and 4) provide experiential skills for students. To introduce students to other disciplines within the college, faculty representing the programs developed streaming video presentations using the following guidelines: 1) Origin of Practice, 2) Scope/:Focus of Practice, 3) Education/Licensure 4) Sites of Practice and 5) Integrative Care (how the practice relates to other traditional and/or alternative practices). The alternative parishioners developed PowerPoint presentations along with streaming video using the same guidelines. The delivery of presentations via blackboard offers flexibility in modifying the content and allows a self-paced course with interactive "chat room" opportunities. The web-based course has been offered to approximately 150 students from various disciplines. Surveys and questionnaires indicate wide acceptance and high approval ratings. The course has met the objective of introducing students to a broader meaning of "Integrative Care" through the creation of an interdisciplinary community of learners.

Family centered integrative holistic health care within a pediatric hospital setting

Susan E Gray, LMT, Judith A Molique, BA, LMT, NCTMB and Michelle Zimmer, MD

Integrative Care \& Holistic Health, Cincinnati Children's Hospital Medical Center, 3333 Burnett Avenue, MLC 4019, Cincinnati, OH 452229, USA. E-mail: [Susan. Gray] [Judy.Molique] [Michelle.Zimmer] @CCHMC.org;

website: www.CincinnatiChildrens.org

The objectives of presentation are (1) to discuss the inception of the Integrative Care and Holistic Health Organication at Cincinnati Children's Hospital Medical Center (CCHMC). (2) to explain the role of the Holistic Health Specialist (HHS) at CCHMC, (3) to explain the holistic health services that are available at CCHMC for patients, families and staff, (4) to present a case study demonstrating the positive impact of holistic health services, and (5) to share the results of a recent integrative care and holistic health services interview. In 1998, CCHMC listened to the needs of families regarding integrative therapies by introducing the Holistic Health Dept. which included two part-time RN, Certified Healing Touch Practitioners (CHTP). Today, under the direction of a Medical Director and a Director of Integrative Care, HHSs are full-time and part-time employees consisting of 13 Licensed Massage Therapists (LMT) and four RN, CHTPs. These practitioners serve the holistic health care needs of patients during all stages of their illness, e.g., inpatient, outpatient and end of life. Holistic Health Specialists work closely with the Interdisciplinary Care Team receiving referrals for services from physicians, nurses, and other team members. Holistic modalities offered at CCHMC include, but are not limited to: Massage Therapy, CranioSacral Therapy, Lymphatic Drainage, Reflexology, Healing Touch, and other forms of energy work, as educationally prepared. Patients access these modalities pre and post operatively, during painful procedures, to address various physiological symptoms including pain reduction, to balancing energy fields, for quieting, calming or relaxing and to help the patient adjust to the hospital environment. A case study will be presented demonstrating the positive effects of holistic health services when integrated into a patient's care plan. HHS also provides comfort, support and education to family and caregivers to help reduce their stress associated with an ill and/or hospitalized child. CCHMC employees also have access to the modalities listed above. Research indicates that a 15-min chair massage may help decrease stress levels during their shift allowing them to be more attentive, caring, efficient, and focused in their work. Results from a convenience sample of $\mathbf{4 5}$ families receiving holistic health services for their child revealed overwhelmingly positive results. Oî 45 interviewees, 44 participants strongly agreed that the HHS were helpful. Holistic Health at CCHMC is valued and continues to grow.

\section{Seasonality of mood disorders and suicide}

Teodor T Postolache, MD, Gloria M Reeves, MD, Gagan Virk, MD, Mei W Kwan, Manana Lapidus, MD, Johanna B Cabassa, MD, Joseph J Soriano and Patricia Langenberg, $\mathrm{PhD}$

Dept. of Psychiatry, University of Maryland School of Medicine, Baltimore, MD, USA. Email: Tpostola@psych. umaniland edu

In contrast to our ancestors, we now live for a considerable amount of time in a microenvironment that somewhat limits our exposure to major fluctuations in 
temperature, light, and other environmental factors. Nevertheless, seasonal changes in behaviors have been identified in humans, similar but to a lesser degree to the profound variation in reproductive and social behaviors in seasonal nonhuman mammals. For instance, recurrent major depression in fall and winter with remission in spring and summer, i.e. a seasonal affective disorder (SAD) with winter pattern has been described; its marker of vulnerability has been proposed to be a seasonal variation in the duration of nocturnal melatonin secretion (as in seasonal mammals), its trigger- a decrease in the duration of day length and its treatment-bright light exposure. Another pattern which has been reported, but not as adequately studied, is summer $S A D$, with recurrent major depression in summer, improvement in fall and winter, a suggested thermoregulatory vulnerability, a trigger consisting of exposure to heat and improvement with cooling. Finally, the most common seasonal patter of decompensation of mood disorders occurs in spring. This spring $S A D$ pattern is particularly dangerous, as it is associated with a spring peak of suicide, an omnipresent epidemiological finding. As cytokines are associated with triggering and exacerbation of symptoms of depression, as a seasonal "tsunami" of tree pollen in spring results in a massive elevation in the incidence of allergic rhinitis, as allergic rhinitis results in cytokine production in the nasal cavity which could be propagated to cytokine production in the brain, we will present evidence for the following (a) a spring pattern of SAD exists and is linked with increased mortality, (b) the peak of suicide in spring occurs via exacerbation of depressive symptoms (c) a vulnerability for a spring SAD is represented by the propensity to develop allergic inflammation (approximately half of the general population in the US), (d) a trigger for spring SAD and the peak in suicide in spring is the massive seasonal peak in aeroallergens, specifically tree pollen, (e) a history of allergy is associated with an increased risk of suicide, and (f) victims of suicides have an increased brain expression of allergy related (TH2) cytokines. Knowledge of the patterns of seasonal depression is conducive to personalized environmentally based therapies. Finally, a better understanding of the connection between aeroallergens, allergy, spring depression and suicide may result in novel preventative interventions in a domain of public health priority.

Family centered integrative holistic health care within a pediatric hospital setting

Susan E Gray, LMT, Judith A Molique, BA, LMT, NCTMB and Michelle Zimmer, MD
Integrative Care and Holistic Health, Cincinnati Children's Hospital Medical Center, 3333 Burnett Avenue, MLC 4019. Cincinnati, OH 452229, USA. E-mail: Susan. gray@CCHMC.org; website: nww.CincinnatiChildrens.org In 1998, Cincinnati Children's Hospital Medical Center (CCHMC) listened to the needs of families regarding integrative therapies by introducing the Holistic Health Dept. which included two part-time RN, Certified Healing Touch Practitioners (CHTP). Today, under the direction of a Medical Director and Director of Integrative Care, Holistic Health Specialists (HHS) are full-time and part-time employees consisting of 13 Licensed Massage Therapists (LMT) and four RN, CHTPs. These practitioners serve the holistic health care needs of patients during all stages of their illness, e.g., inpatient, outpatient and end of life. HHS work closely with the Interdisciplinary Care Team receiving referrals for services from physicians, nurses and other team members. Holistic modalities offered at CCHMC include, but are not limited to: Massage Therapy, CranioSacral Therapy, Lymphatic Drainage, Reflexology, Healing Touch and other forms of energy work, as educationally prepared. Patients access these modalities pre and post operatively, during painful procedures, to address various physiological symptoms including pain reduction, to balancing energy fields, for quieting, calming or relaxing and to help the patient adjust to the hospital environment. HHS also provides comfort, support and education to family and caregivers to heip reduce their stress associated with an ill and/or hospitalized child. CCHMC employees also have access to the modalities listed above. The future of Integrative Care and Holistic Health continues to develop and grow to meet the individual needs of our patients, families and staff as these services become more fully integrated into all areas of patient care. A collection of personal statements from real life experiences from patients, families and staff will be displayed.

A review of garlic as a potential lipid-lowering agent Amit M Deokar, MD, MPH and Shawn J Smith, MD Division of Adolescent Medicine. University of Kentucky, Lexington, Kentucky, USA.E-mail: amit-deokar@uky.edu Cardiovascular diseases continue to be the major cause of death and disability in developed nations. Approximately $29 \%$ of all deaths in the USA are due to heart diseases. Various factors promote the development of coronary artery disease. One of the important factors is diet-related. An increase in LDL, TG, and total cholesterol are responsible for atherosclerosis formation 
and subsequent cardiovascular diseases. In the year 2006, the cost of health care, productivity loss, and medications for cardiovascular disease was $\sim 403$ billion dollars. Various studies have shown that by lowering high total cholesterol, the risk of death from a heart attack is greatly reduced. Diets that are abundant in fruits and vegetables have a lower association of cardiovascular related deaths. One such ingredient is Garlic. Believed to have originated in Asia, garlic/garlic extract has traditionally been used to enhance mental and physical health. Animal and human studies have shown the lipid lowering characteristics of garlic. Of the many factors in garlic, the anti-thrombotic, antioxidant, and fibrinolytic properties play a vital role in protecting against some of the cardiovascular diseases resulting from dyslipidemia. There have been numerous conflicting reports about the benefits of garlic in cardiovascular health, especially so in children. Complementary medicine is picking up great momentum in the western hemisphere. Various herbal medications including garlic need further evaluation through controlled studies.

Family centered approach to treatment of anorexia nervosa offers promising outlook

Shawn J Smith, MD and Amit Deokar, MD, MPH

Division of Adolescent Medicine, Dept of Pediatrics, University of Kentucky, Lexington, KY, USA. E-mail: shawnjsmith@uky.edu

In the USA and particularly, the state of Kentucky, we are experiencing increasing rates of childhood and adolescent obesity. Despite this, data also suggests that there is an increase in the prevalence rates for anorexia nervosa (AN) in the adolescent and young adult population. Anorexia nervosa has the highest mortality of all psychiatric conditions. This disorder is extremely difficult to treat and relapse is extremely common. In the age when insurance companies are becoming more and more reluctant to cover inpatient expenses, outpatient therapy has become even more important and common in the treatment of eating disorders. Because of this miny different approaches have been applied, yet little has been actually researched. The small number of clinical studies that have looked at individual versus family centered therapy for the treatment of AN in the adolescent population have shown promising results with significant improvements at 5 year follow up and a decrease in relapse rates. The most published and studied family centered approach is the Maudsley approach, which requires that the patient is under the age of 18 and living with at least one parent or caregiver. This is a treatment plan that is divided into three stages. The first stage hands responsibility to the parent. A very important element to this stage is that any pathology that exists within the family dynamics is overlooked. Blame is taken away from the family and they in turn, must learn to separate the illness from the child. The therapist acts as a facilitator for this. The etiology of the illness is not addressed. Regaining weight is the foundation of this first stage. The second stage is begun once the child has reached an appropriate weight. Once this occurs, the therapist facilitates the family to begin to relinquish control back to the adolescent. Finally, the third stage focuses on more general adolescent related issues and how AN impacts these such as sexuality and autonomy. Some argue that this approach forces the adolescent to be deprived of autonomy and the ability to learn to separate from their parents at a time when these skills are crucial to adolescent development. While this may be true, this family-centered approach to the treatment of adolescents with AN has been shown to have promising outcomes. This approach clearly warrants further studies.

Heavy Petal A to Z: Herbs from arnica to zingiber in the adolescent patient

Cora Collette Breuner, MD, MPH.

Associate Professor of Pediatrics, Division of Adolescent Medicine, Institution University of Washington. Children's Hospital and Regional Medical Center 4800 Sand Point Way NE 4H-I Seattle, WA 98105. Phone 206 987-2049 Fax 206 987-3959

Herbal medicine in the USA is a vast subject which can be looked at from many different perspectives. A historian would look at the natural progression of herbs in the context of modern medicine, and a pharmacologist would observe safety and efficacy standards. As health care providers we tend to share beliefs of many subgroups with the utmost importance being the health of our patients. From the Harvard studies on complementary and alternative medicine (CAM) use in 1990 and 1997, the use of self-prescribed herbal remedies within the U.S. increased from $2.5 \%$ in 1990 to $12.1 \%$ in 1997. The proportion of individuals consulting practitioners of herbal medicine rose from $10.2 \%$ to $15.1 \%$ and they spent around $\$ 5$ billion on herbal medicines. Nearly one in five individuals taking prescription medicines was also taking herbs or high-dose vitamin supplements. Importantly, the herbal medicine user takes conventional prescribed or self-prescribed drugs 
concomitantly which increases the potential for herbdrug interactions. In this workshop participants will get a brief update on the usage patterns of herbals medicines in the adolescent population. The most commonly used herbal medicines will also be discussed as well as less well know herbs such as Arnica, Astralagus, Camellia and Butterbur. Emphasis will be placed on the efficacy and safety of herbal medicines. Participants are encouraged to being questions and their own cases to the workshop. A bibliography, resource list will be distributed as well as information on how to receive up to the minute updates on herbal medicines.

Psycho-phenomenological holistic competence in complex PTSD patients: A project description

Rasmus Revsbech, BAPsych, MSci

University of Copenhagen. Strandiejen 30, st. -32100 Copenhagen O Phone: 004560929542

E-mail: revsbech@stud.ku.dkIVeb: www.myspace.com/ rasmusrevsbech and wuw.myspace.com/juttalane

"Complex PTSD" as a term is used with adults, not seeming to live a life in existential harmony due to early childhood/attachment trauma while on the surface seeming "normal". Due to newness of this diagnosis it is extremely important to do much more research in this particular area. Research in this field should include the concepts of life ontology, reflexivity and metareflection, to clarify the ability to live an authentic holistically reflected life in the property of common psychology as its own psychological ontology discipline. This is done due to the fact that a given Complex PTSD patient most often has to holistically change his/her way of constituting a philosophy of life. Meaning to reflect on his or her life and view it as a whole. Otherwise change so profoundly necessary and demanding in an adult suffering form Complex PTSD will most likely not be possible. The complex posttraumatic self and its development of what the presenter has named "a psycho-phenomenological holistic competence" as a certain way of reflecting will hereafter be presented as what should be achieved by the Complex PTSD patient. This is due to the fact that treatment of Complex PTSD patients often are adults struggling existentially, thus not integrating and transcending trauma and achieving a heightened sense of coherence and meaning in viewing their life as a whole. To clarify the universalities in the field of treatment of Complex PTSD, a model of the development of the posttraumatic self should be combined with a clear definition of the teleology of psychology as a treatment phenomenon with Complex PTSD patients. Now the core (very broad) questions here after are: How is this psycho-phenomenological holistic competence developed? What about the idiosyncratic relative factor as ontology? And what research will be necessary and most crucial?

\section{Eating disorders and CAM therapies \\ Cora Collette Breuner, MD, MPH.}

Associate Professor of Pediatrics, Division of Adolescent Medicine, Institution University of Washington. Children's Hospital and Regional Medical Center 4800 Sand Point Way NE 4H-I Seattle, WA 98105. Phone 206 987-2049 Fax 206987-3959

Eating disorders, including anorexia nervosa, bulimia nervosa, and eating disorders not otherwise specified, typically emerge in early adolcscence with onset shortly after puberty. Recent estimates suggest that the prevalence of anorexia ranges between $0.5 \%-1 \%$ among adolescent females and is approximately $0.02 \%$ in adolescent males. Adolescents frequently use herbal therapies and supplements for weight loss, including caffeine, hoodia, and guarana. Yet CAM therapies can be extremely beneficial in the treatment programs for adolescents with eating disorders. Attendees will learn an overview of existing treatments including massage, yoga, meditation, acupuncture and naturopathic remedies. Information on evidence based treatments and safety information will be disseminated.

Towards interprofessional understanding: Perceptions of allopathic and holistic practitioners about medicine and teaching

William G Elder, Jr, PhD, ' Deborah L Crooks, PhD, ${ }^{2}$ Samuel C Matheny, MD, MPH, ${ }^{1}$ Chester D Jennings, $\mathrm{MD}^{3}$ and Geza P Bruckner ${ }^{4}$

'Dept. of Family and Community Medicine, College of Medicine, ${ }^{2}$ Dept. of Anthropology, College of Arts and Sciences, ${ }^{3}$ Senior Associate Dean for Medical Education, College of Medicine, 'Dept. of Clinical Nutrition, College of Health Sciences, University of Kentucky, Lexington, Kentucky, USA. Correspondence: William G Elder, University of Kentucky College of Medicine, K309 Kentucky, Clinic, Lexington KY 40502, USA. Office: 859-257-9569, Fux: 859-323-6661; E-mail: u'elder@email.uky.edu

Objectives: Mainstream health care providers and holistic health practitioners should seek to find ways to collaborate and work together to provide the best possible care of our patients and clients. Responding to 
suggestions that physicians are obligated to fully inquire about complementary and alternative medicine (CAM) use and its scientific evidence, to acknowledge patients' health beliefs and practices, and to accommodate diverse healing practices, our project created an advisory committee composed of holistic practitioners and institutional personnel to incorporate CAM related information into health professions training. We report on the collaborative process and describe group members' perceptions of medicine and clinical teaching. Methods: Information collected from the first two years' quarterly meetings, the first annual retreat and other venues were analyzed in conjunction with semistructured in-person interviews of ten biomedical and CAM practitioner committee members. Data were analyzed using qualitative methodology and N5 software to identify themes and patterns. Results: Analysis confirmed expectations that allopathic and holistic AC members held different views of health and healing. Member comments reflected points of tension which clustered into three intertwined themes: what constitutes evidence, interaction with the patient, and the relative importance of experience in learning. Conclusion: Differences were frequent but did not obviate common goals or collaboration. Results demonstrate the potential for collaboration between these groups. Our members' perceptions of medicine and clinical teaching should be useful to others seeking to improve collaboration. Acknowledgment: This project was supported by grant 5 R25 AT000682 from the US National Institutes of Health, National Center for Complementary and Alternative Medicine (NCCAM).

\footnotetext{
Aging in Israel. A program for home care Judith Kandel, MA Matan, Rehov Weizmann 60, IL-44250 Kfar Saba, Israel E-mail: kandelii@zahav.net.il

Since 1955, the population of Israelis over 65 years of age has increased sevenfold, while the general population has increased just a bit more than threefold. Israeli citizens in this age group now account for $10 \%$ of the population, up from $4 \%$ in the 1950 s. Among Jews alone, those 65 years and over represent about 12\% (as compared with 3\% among Arabs). Even more startling is the increase in the number of "old-old"-i.e., those who have already celebrated their $75^{\text {th }}$ birthday. Now there are some 250,000 such men and women, 10 times as many as in the $1950 \mathrm{~s}$. This presentation will describe a holistic home care program for older people in the central part of Israel.
}

Integrative medicine training activities and learner self-awareness

William G Elder, Jr, PhD, ${ }^{1}$ David Rakel, $\mathrm{MD},{ }^{2}$ Carol Hustedde, $\mathrm{PhD}^{1}$ and $\mathrm{ML}$ Love, $\mathrm{PhD}^{\prime}$

'Dept. of Family and Community Medicine, College of Medicine, University of Kentucky. Lexington, Kentucky, USA, ${ }^{2}$ Dept. of Family Medicine, University of Wisconsin, Madison, Wisconsin, USA. Correspondence: William G Elder, University of Kentucky College of Medicine, K309 Kentucky Clinic, Lexington KY 40502, USA. Office: 859257-9569, Fax: 859-323-6661; E-mail: welder@email. uky.edu

Most educators would agree that integrative medicine curricular activities have potential to increase knowledge and skills about complementary and alternative medicine (CAM). However, there is a possibility that the unique content and activities associated with CAM curriculum may serve to increase learner self-awareness and enhance integrative function abilities. Self-awareness is an intrapersonal process that can influence professional behavior in complex situations. Self-awareness is evidenced by intellectual curiosity and comfort investigating personal, as well as patient emotions and attitudes; creativity and competence with learning situations and, better recognition of personal errors, refined technical skills, and evidence-based decisions. This poster will report activities and curriculum developed by 16 National Institutes of Health-funded education projects to increase learners' self-awareness. Methods: Sixteen Integrative Medicine Education projects responded to electronic surveys that generated information about self awareness curricular elements and perceived impact on trainees. Four programs (University of Kentucky, Georgetown University, Tufts University, and the American Medical Student Association) provided in depth descriptions of their activities which will be described. Results and Conclusion: Methodologies ranged from those which were strictly cognitive via lectures to experiential activities where the goals ranged from simple exposure to skills acquisition. Most projects saw mind-body, self-care or spirituality experiences as means to foster self-awareness. Several projects viewed mind-body training, through direct experience with the modality, as an opportunity to expand the learner's view of what constitutes health. NIH / NCCAM funded educators believed that they were able to impact trainees' self-awareness and through activities emphasizing patient-centered healing, self-care, reduced bias and deep understanding of CAM. Acknowledgment: This project was supported by grant 
5 R25 AT000682 from the USA National Institutes of Health, National Center for Complementary and Alternative Medicine (NCCAM).

An experiential, process-oriented approach to resolving "no name" diseases among Chernobyl liquidators.

Joseph Goodbread, Dr. Sc. Techn., Dipl. P.O Psych.', Kate Jote, MA, RSMT, Dipl. P.O Psych. ${ }^{2}$

'Process Work Institute, Portland, Oregon, $2049 \mathrm{NW}$ Hoyt, Portland, Oregon 97210 (jgoodbread@igc.org), ${ }^{2}$ Process Work Institute, Portland, Oregon, $2049 \mathrm{NW}$ Hoyt, Portland, Oregon 97210 (kate@katejobe.com)

Many of the 750,000 "liquidators" who decontaminated the reactor site after the Chernobyl disaster suffered from diverse symptoms that defy organization under any accepted radiation-related diagnoses. Lack of a diagnosis detracts from the liquidators' quality of life, by denying them access to medical and social resources, as well as marginalizing them by branding them as malingerers. In this study we applied the methods of Process Work - a mind-body, awareness-based therapeutic modality that focuses on the patient's subjective experience of his or her physical symptoms-to work with a group of Chernobyl liquidators. All suffered from debilitating physical and mental symptoms that rendered them incapable of either working or campaigning vigorously for promised social benefits. We focus on the case of one liquidator-Andrei - who suffered from severe pains tentatively attributed by his doctor to pancreatitis, with no causal relation to his exposure to intense radiation at Chernobyl. We show how, by exploring and unfolding his somatic experience through imagery, movement, and sensory-grounded (rather than interpretive) perception of the pain, he obtained access to inner resources of strength, endurance and optimism of which he had been deprived by his illness and social marginalization. His experience helped him reach beyond the boundaries of his known identity to improve his quality of life in general, even beyond coping with his symptoms. We show how process work operates on three distinct levels of such "no name" diseases-the individual, by improving quality of life; the social, by helping the sufferer become re-integrated into mainstream society; and the global, by helping the social system re-integrate the sufferer's otherwise marginalized firsthand experience of catastrophic social events. This holistic approach insures the method is neither socially regressive (merely healing the individual from sociallyinduced ills without addressing social stressors) nor, on the other hand, exploitative of the individual's pain for society's good. Finally, we show how this method contributes to improved quality of life in situations as diverse as severe illness, comatose and near-death experience, complexes of mental-social disorders (homelessness, addiction, co-occurring disorders), and social marginalization in general. 